Review

\title{
Antiretroviral Drug Interactions: Overview of Interactions Involving New and Investigational Agents and the Role of Therapeutic Drug Monitoring for Management
}

\author{
R. Chris Rathbun * and Michelle D. Liedtke \\ Department of Pharmacy: Clinical \& Administrative Sciences, College of Pharmacy, University of \\ Oklahoma Health Sciences Center, Oklahoma City, OK 73117, USA; \\ E-Mail: Michelle-Liedtke@ouhsc.edu
}

* Author to whom correspondence should be addressed; E-Mail: Chris-Rathbun@ouhsc.edu; Tel.: +1-405-271-6878; Fax: +1-405-271-6430.

Received: 5 August 2011; in revised form: 15 September 2011 / Accepted: 8 October 2011 / Published: 21 October 2011

\begin{abstract}
Antiretrovirals are prone to drug-drug and drug-food interactions that can result in subtherapeutic or supratherapeutic concentrations. Interactions between antiretrovirals and medications for other diseases are common due to shared metabolism through cytochrome P450 (CYP450) and uridine diphosphate glucuronosyltransferase (UGT) enzymes and transport by membrane proteins (e.g., p-glycoprotein, organic aniontransporting polypeptide). The clinical significance of antiretroviral drug interactions is reviewed, with a focus on new and investigational agents. An overview of the mechanistic basis for drug interactions and the effect of individual antiretrovirals on CYP450 and UGT isoforms are provided. Interactions between antiretrovirals and medications for other co-morbidities are summarized. The role of therapeutic drug monitoring in the detection and management of antiretroviral drug interactions is also briefly discussed.
\end{abstract}

Keywords: antiretrovirals; pharmacokinetics; drug interactions; protease inhibitors; non-nucleoside reverse transcriptase inhibitors; chemokine receptor antagonists; integrase inhibitors; therapeutic drug monitoring 


\section{Introduction}

The introduction of triple combination antiretroviral therapy has led to dramatic reductions in HIVrelated morbidity and mortality [1]. Despite improvements in patient outcomes, selection of antiretroviral therapy remains challenging for clinicians due to resistance considerations, overlapping drug toxicities, and drug-drug and drug-food interactions. Drug-drug interactions among antiretrovirals are common and often require dose modification to mitigate unwanted adverse events and to sustain therapeutic concentrations. As HIV management has migrated from treatment of an acute infection to a chronic disease, the potential for antiretroviral drug interactions with medications for other chronic diseases has increased. It is important for clinicians to carefully consider the consequences of combining antiretrovirals with some drugs where the risk of adverse events or treatment failure may be increased due to unfavorable drug interactions.

This article provides an overview of common antiretroviral pharmacokinetic drug interactions, with an emphasis on newer antiretroviral agents introduced in the past five years and promising investigational agents. The mechanistic basis for drug interactions and metabolism of antiretroviral classes is briefly reviewed, followed by detailed discussion of the drug interaction potential between different antiretrovirals and with various drugs and drug classes. Recommendations for clinical management are also provided. The role of therapeutic drug monitoring in the detection and management of drug interactions is also discussed.

\section{Mechanisms of Interaction}

Drug interactions involving antiretrovirals can be classified as either pharmacokinetic or pharmacodynamic based on the mechanism of interaction. Pharmacokinetic interactions impact the absorption, distribution, metabolism, or excretion of antiretrovirals, whereas pharmacodynamic interactions result in synergistic, additive, or antagonistic drug response when they occur. Many antiretrovirals are substrates for transport proteins (e.g., organic anion-transporting polypeptide [OATP] 1B1, OATP1B3, and organic cation protein 1 [OCT1] in the liver; MDR1, breast cancer resistance protein [BCRP] and multidrug resistance protein 2 [MRP2] in the gut and liver) and can exhibit altered absorption, distribution, or excretion when coadministered with drugs that affect these proteins [2].

Interactions involving altered metabolism occur as a result of induction or inhibition of specific metabolic enzymes. Inhibition of metabolism most commonly results from competitive, non-competitive, or mechanism-based inhibition [3]. Competitive inhibition occurs when concentration of the inhibiting agent is sufficiently high to block metabolic conversion of the affected drug at the respective isoenzyme. Non-competitive inhibition occurs from allosteric inhibition, where binding to a site proximal to the catalytic binding site results in a conformational change in the catalytic site. Mechanism-based inhibition occurs when reactive intermediates bind irreversibly to the catalytic binding site [3]. Several antiretrovirals (ritonavir, amprenavir, nelfinavir, delavirdine) have been identified as mechanism-based inhibitors and are associated with clinically significant interactions with other drugs [4]. 
Induction of metabolism can occur when binding of drugs to nuclear receptors (e.g., pregnane $\mathrm{X}$ receptor [PXR], constitutive androstane receptor [CAR], hydrocarbon receptor) causes transcriptional factor activation, resulting in increased production of metabolic enzyme [5]. Individual protease inhibitors and NNRTIs have been found to be ligands for PXR and CAR, resulting in induction of specific isoenzymes or transport proteins (e.g., MDR1) that can decrease systemic exposure and increase the risk for therapeutic failure [6]. The timing of drug coadministration during pharmacokinetic interaction studies must be considered since agents that function as metabolic inducers at steady-state concentrations can exhibit inhibition during the first several weeks of therapy, leading to incorrect conclusions regarding their metabolic effects.

Pharmacogenetics can also determine whether a particular metabolic interaction is clinically significant. Polymorphic metabolism in CYP450 isoforms can influence the magnitude of change in serum concentration that is observed by either attenuating or magnifying the extent of reduction or increase. Cytochrome P450 (CYP) 3A4, CYP2B6, CYP2C9, CYPC19 and UGT all exhibit polymorphic metabolism and, therefore, can influence the significance of drug-drug interactions in specific patient populations [7-9].

\section{Interactions between Antiretrovirals}

\subsection{Protease Inhibitors}

All currently-approved HIV protease inhibitors are metabolized by CYP450, primarily CYP3A4, and are substrates for $p$-glycoprotein, making interactions likely between protease inhibitors and other antiretrovirals metabolized by CYP450. Ritonavir "boosting" is commonly employed to prolong the systemic exposure of other protease inhibitors and can further increase the potential for clinically significant interactions because of the potent inhibitive and inductive effects of ritonavir on various CYP isoforms. Ritonavir is known to autoinduce its own metabolism through CYP3A4, requiring dosage increases to maintain therapeutic concentrations when used clinically as the sole protease inhibitor (600 mg twice daily) in the antiretroviral regimen [10]. Due to the potent mechanism-based inhibitory effects of ritonavir on CYP3A4 (50\% inhibitory concentration [ $\left.\mathrm{IC}_{50}\right]: 0.05-1.4 \mu \mathrm{g} / \mathrm{mL}$ ), ritonavir is believed to function as an inhibitor for CYP3A4 substrates with chronic administration [10,11]. In addition, the low doses of ritonavir used for pharmacokinetic boosting (100-200 mg/day) are less likely to be associated with significant induction of CYP3A4 based on the decreased extent of induction predicted by pharmacokinetic modeling at lower ritonavir doses (12\% induction at $200 \mathrm{mg}$ twice daily versus $45 \%$ at $500 \mathrm{mg}$ twice daily) [10]. This contrasts with the apparent induction of other CYP isoforms (CYP2C9/19, CYP2B6, CYP1A2) with ritonavir [12] that can lead to clinically significant interactions with other medications [13].

Tipranavir, darunavir, saquinavir, and lopinavir all require ritonavir boosting for clinical use; therefore, the interaction profile of these agents is determined in part by the effect of ritonavir on individual isoenzymes. Many other protease inhibitors (atazanavir, indinavir, fosamprenavir) are commonly boosted with ritonavir to optimize their pharmacokinetic profile, simplify their dosing frequency, and improve their side effect profile. Interactions among protease inhibitors can be complex due to varied effects on specific CYP enzymes and may result in subtherapeutic concentrations or 
additive toxicity. This is exemplified by the dual interaction between lopinavir/ritonavir and fosamprenavir, where coadministration results in suboptimal serum concentrations (48\% and 64\% reduction in lopinavir and amprenavir systemic exposures, respectively) that cannot be reliably overcome by staggering administration or dose modification $[14,15]$.

Table 1. Metabolic Effects for Antiretrovirals [6,12,18-36].

\begin{tabular}{|c|c|c|c|c|c|c|c|c|}
\hline \multirow{2}{*}{\multicolumn{2}{|c|}{ Antiretroviral }} & \multicolumn{7}{|c|}{ Predicted Enzyme Effect } \\
\hline & & 3A4 & $2 B 6$ & $2 \mathrm{C} 9$ & $2 \mathrm{C} 19$ & $2 D 6$ & $1 \mathrm{~A} 2$ & UGT \\
\hline \multirow{9}{*}{$\frac{n}{a}$} & Atazanavir & & - & & $-^{\mathrm{a}}$ & - & & \\
\hline & Darunavir/r & & & & & $-{ }^{a}$ & & \\
\hline & Fosamprenavir & & & - & $-{ }^{\mathrm{a}}$ & - & - & - \\
\hline & Indinavir & & - & - & - & $-{ }^{\mathrm{a}}$ & - & \\
\hline & Lopinavir/r & & & & & $-{ }^{\mathrm{a}}$ & & \\
\hline & Nelfinavir & & - & & & - & & \\
\hline & Ritonavir & $\mathrm{b}$ & & & & 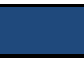 & & \\
\hline & Saquinavir & & - & $-{ }^{\mathrm{a}}$ & - & - & - & - \\
\hline & Tipranavir/r & & & & & & & \\
\hline \multirow{5}{*}{$\frac{\tilde{n}}{\underline{\underline{z}}}$} & Delavirdine & & - & & & $-{ }^{\mathrm{a}}$ & - & - \\
\hline & Efavirenz & & & & & & & \\
\hline & Etravirine & & & & & - & - & \\
\hline & Nevirapine & & & & - & - & - & \\
\hline & Rilpivirine & & & $*$ & & $*$ & & $*$ \\
\hline \multirow{3}{*}{$\begin{array}{l}E \\
\underline{Z} \\
Z\end{array}$} & Raltegravir & - & - & - & - & - & - & \\
\hline & Elvitegravir/r & & $*$ & $*$ & $*$ & $*$ & $*$ & \\
\hline & Dolutegravir & & $*$ & $*$ & $*$ & * & $*$ & \\
\hline$\lesssim$ & Maraviroc & & - & - & - & - & - & - \\
\hline
\end{tabular}

The predicted metabolic effects of antiretroviral agents on various cytochrome (CYP) P450 isoenzymes and uridine diphosphate glucuronosyltransferase (UGT) are illustrated according to the following: $\square$ inhibition, $\square$ induction, $\square$ mixed induction/inhibition, $\square$ substrate, [ ] no significant effect, [*] not determined. The clinical significance of specific interactions between antiretrovirals and other drugs will be determined by the therapeutic and toxicity indices of the affected drug(s). The use of low-dose ritonavir for pharmacokinetic boosting is denoted by lowercase " $/ \mathrm{r}$ " following individual antiretrovirals. ${ }^{a}$ Enzyme not affected at clinically relevant antiretroviral concentrations. ${ }^{b}$ Autoinduction of CYP3A4 by ritonavir is observed during the first 2 weeks of therapy, but CYP3A4 inhibition is most commonly evident with chronic therapy. PIs $=$ protease inhibitors, NNRTIs = non-nucleoside reverse-transcriptase inhibitors, INSTIs $=$ integrase strand transfer inhibitors, $\mathrm{CRA}=\mathrm{CCR} 5$ receptor antagonist

Alteration of the pharmacokinetics of ritonavir has also been noted when low-dose ritonavir is combined with various protease inhibitors as a boosting agent and further exemplifies the complexity of interactions between protease inhibitors. Ritonavir concentrations are lower when ritonavir is individually combined with lopinavir, fosamprenavir, and tipranavir (54\%, 40\%, and 90\%, respectively) presumably as a result of induction of CYP3A4 (lopinavir, fosamprenavir) and/or $p$-glycoprotein (tipranavir); slightly lower ritonavir concentrations (14\%) have also been reported with 
darunavir [16]. In contrast, increases in ritonavir systemic exposure are noted with atazanavir and indinavir (69\% and 72\%, respectively), potentially reflecting CYP3A4 inhibition [16]. The clinical significance of these changes varies since the ritonavir exposure required for boosting of individual protease inhibitors is different depending on the site of inhibition (gut versus gut/hepatic) [16,17] and is typically optimized prior to widespread clinical use through formal pharmacokinetic studies to achieve the desired systemic exposure for each protease inhibitor. The predicted metabolic effects of individual protease inhibitors on various CYP and UGT enzymes are depicted in Table 1.

Darunavir/Ritonavir: Darunavir is the newest protease inhibitor to be approved for HIV infection in the past five years and requires coadministration with ritonavir for clinical use. Ritonavir coadministration (100 mg twice daily) increased the absolute bioavailability of darunavir in healthy volunteers from $37 \%$ to $82 \%$ and produced a 14 -fold increase in systemic exposure [37]. Ritonavir doses above $100 \mathrm{mg}$ twice daily do not produce further increases in the area under the concentrationtime curve (AUC) for darunavir [38]. Administration of darunavir/ritonavir with food increases bioavailability by $30 \%$ irrespective of whether a low or high-fat meal is administered [39].

The potential for interaction between darunavir/ritonavir and NNRTIs has been evaluated in healthy, HIV-seronegative volunteers and patients with HIV infection. Administration of darunavir oral solution (non-commercial formulation)/ritonavir (300 mg/100 mg twice daily) with efavirenz (600 mg daily) in healthy volunteers resulted in a $31 \%$ reduction in the minimum concentration $\left(C_{\min }\right.$ for darunavir and an increase in efavirenz AUC by $21 \%$. Caution should be exercised with darunavir and efavirenz coadministration given the limited safety data available from clinical studies and the frequency of rash (3/12 subjects) observed during this small trial [40]. A 27\% increase in nevirapine AUC and $18-47 \%$ increase in $C_{\min }$ were observed when nevirapine (200 $\mathrm{mg}$ twice daily) was administered with two separate formulations of darunavir ( $300 \mathrm{mg}$ by oral solution, $400 \mathrm{mg}$ tablet) boosted with ritonavir twice daily in HIV-infected patients. Slight elevations in darunavir AUC and $C_{\min }$ (9-24\% and 2-23\%, respectively) were also observed depending on the darunavir formulation. The observed changes are not considered to be clinically significant based on safety and efficacy results from long-term clinical studies where the combination of nevirapine and darunavir/ritonavir was used [41]. Comparable changes in nevirapine and efavirenz pharmacokinetics are projected when nevirapine and efavirenz are administered with the higher doses of darunavir/ritonavir $(600 \mathrm{mg} / 100 \mathrm{mg}$ twice daily) used clinically [40,41]. Etravirine $100 \mathrm{mg}$ twice daily had no effect on darunavir serum concentrations; no significant interaction is predicted with higher etravirine doses (200 mg twice daily) [42].

Clinically significant interactions between darunavir/ritonavir and other protease inhibitors have also been reported. A large reduction in darunavir AUC was observed when given with lopinavir/ritonavir (400/100 mg or 533/133 mg twice daily) in HIV-infected patients. Increase in the darunavir/ritonavir dose from $600 / 100 \mathrm{mg}$ to $1200 / 100 \mathrm{mg}$ twice daily resulted in AUC values that remained 38\% lower than darunavir/ritonavir 600/100 mg twice daily without lopinavir/ritonavir [43]. Darunavir was similarly reduced by coadministration with saquinavir/ritonavir $(1000 \mathrm{mg} / 100 \mathrm{mg}$ twice daily) in healthy volunteers where a $26 \%$ reduction in darunavir AUC and $42 \%$ reduction in $C_{\min }$ was observed [44]. Dosing strategies for darunavir to overcome the interactions with lopinavir/ritonavir and saquinavir are not established; therefore, the combination of lopinavir/ritonavir or saquinavir with 
darunavir is not recommended for clinical use $[43,44]$. No significant change in darunavir AUC was noted when darunavir/ritonavir (400/100 mg twice daily) was given with atazanavir (300 mg daily); however, atazanavir $\mathrm{C}_{\min }$ increased by $52 \%$. Since the safety of atazanavir systemic exposures in this range is already established, this increase is not considered clinically significant [45]. Coadministration of indinavir (800 mg twice daily) and darunavir/ritonavir (400 mg/100 mg twice daily) in healthy volunteers results in an increase in indinavir AUC and $C_{\min }(23 \%$ and $125 \%$, respectively) and darunavir AUC and $C_{\min }$ (24\% and 44\%, respectively) compared with indinavir/ritonavir $(800 \mathrm{mg} / 100$ $\mathrm{mg}$ twice daily) alone; reduction in the indinavir dose to $600 \mathrm{mg}$ twice daily is recommended if intolerance develops [46]. Raltegravir and maraviroc have no significant effect on the pharmacokinetics of darunavir/ritonavir. The effect of darunavir/ritonavir on the pharmacokinetics of raltegravir and maraviroc will be reviewed in the respective sections for these agents.

\subsection{Non-Nucleoside Reverse-Transcriptase Inhibitors (NNRTIs)}

The currently-approved NNRTIs (efavirenz, nevirapine, etravirine, delavirdine, rilpivirine) are substrates for CYP2B6 and/or CYP3A4. Rilpivirine (formerly TMC278) is the newest NNRTI to be approved in the United States and is a substrate for CYP3A4, CYP2C19, and CYP1A1, with CYP2C8/9/10 serving as alternative pathways [32]. Important food interactions exist with some NNRTIs. The bioavailability of efavirenz is increased significantly (AUC by $28 \%$, maximum concentration $\left[C_{\max }\right]$ by $\left.79 \%\right)$ with a high-fat meal $(1000 \mathrm{kcal}, 500-600 \mathrm{kcal}$ from fat) according to product labeling, resulting in a higher risk for central nervous system side effects (e.g., vivid dreams, somnolence) [47]. Coadministration with food is discouraged when initiating efavirenz but can be considered in patients who exhibit limited central nervous system effects with continued use. Etravirine exhibits improved bioavailability with food versus fasting, where systemic exposure is reduced by $51 \%$, and should be administered with food according to manufacturer recommendations [48]. The bioavailability of rilpivirine is decreased by $43 \%$ to $50 \%$ when taken on an empty stomach or with a high-protein nutritional drink ( 8 grams of fat, $300 \mathrm{kcal}$ ) compared with a standard meal (21 grams of fat, $533 \mathrm{kcal}$ ) but is unaffected by a high fat meal (56 grams of fat, $928 \mathrm{kcal})$ [49].

Efavirenz and etravirine exhibit a mixed interaction profile, where induction or inhibition of specific CYP450 isoforms may be observed; whereas nevirapine primarily functions as an inducer and delavirdine as an inhibitor. Efavirenz is a weak inhibitor of CYP1A2 and CYP2D6 in vitro, a strong inhibitor of CYP2C9 and CYP2C19, and an inducer of CYP3A4 and CYP2B6 [6,47,50] Induction of CYP2C19 in vivo by efavirenz is suggested based on clinical evidence [28]. Etravirine induces CYP3A4, CYP2B6, and uridine diphosphate glucuronosyltransferase (UGT) and inhibits CYP2C9 and CYP2C19 [51]. Nevirapine induces CYP3A4, CYP2B6, CYP2C9, and possibly UGT [30,31]. Delavirdine functions primarily as an inhibitor of CYP3A4, CYP2C9, and CYP2C19 [50]. Rilpivirine exhibits weak induction of CYP3A4 and CYP2C19 at higher doses (150-300 mg) in vivo, weak induction of CYP1A2 and CYP2B6 in vitro, and is prone to having its metabolism altered by strong CYP3A4 inhibitors [52]. 
Etravirine: The drug interaction profile of etravirine with other antiretrovirals has been studied fairly extensively. Serum concentrations for some protease inhibitors are reduced by etravirine as a result of CYP3A4 induction. Increase or decrease in etravirine systemic exposure is also observed in some instances depending on the specific protease inhibitor, presumably due to altered metabolism through CYP3A4 or CYP2C9/19. Indinavir geometric mean ratios (GMRs) for AUC, $C_{\max }$, and $C_{\min }$ with and without etravirine (1600 mg twice daily; TF035 formulation) are $0.54,0.72$, and 0.24 , respectively; whereas etravirine AUC, $C_{\max }$, and $C_{\min }$ are increased by approximately 50\% [53]. Saquinavir AUC and $C_{\max }$, are $48 \%$ and $54 \%$ lower, respectively, with etravirine following a single $1200 \mathrm{mg}$ saquinavir dose but are unaffected when given with low-dose ritonavir [53]. Coadministration of etravirine and atazanavir with or without ritonavir results in reduction in atazanavir $C_{\min }(38-47 \%)$ and increased etravirine systemic exposure (30-50\%); the clinical significance of these changes remains to be determined [54]. Coadministration of etravirine and fosamprenavir/ritonavir $(700 \mathrm{mg} / 100 \mathrm{mg}$ twice daily) increased amprenavir AUC, $C_{\max }$, and $C_{\min }$, by $69 \%, 62 \%$, and $77 \%$, respectively, and should be used with caution because of the increased potential for amprenavir-related adverse events (e.g., rash, nausea) [55]. No significant interaction is noted between lopinavir/ritonavir and etravirine [53]. Darunavir/ritonavir (600 mg/100 mg twice daily) reduces etravirine AUC and $C_{\min }$ by $37 \%$ and $49 \%$, respectively, but was associated with effective viral suppression in the DUET-1 and DUET-2 studies [42,56]. Full-dose ritonavir (600 mg twice daily) decreases etravirine AUC and $\mathrm{C}_{\max }$ by $46 \%$ and $32 \%$, respectively [57]. Etravirine serum concentrations are significantly reduced (70-80\%) by tipranavir/ritonavir [58].

As a general rule, etravirine should not be administered with unboosted protease inhibitors, full-dose ritonavir, or tipranavir/ritonavir but can be safely used with darunavir/ritonavir, lopinavir/ritonavir, and saquinavir/ritonavir. Clinically significant interactions are not expected to occur between etravirine and nucleoside reverse-transcriptase inhibitors (NRTIs). Etravirine should not be coadministered with other NNRTIs because of the potential for unfavorable metabolic interactions between agents and the potential for cross resistance. Interactions between etravirine and maraviroc and raltegravir have also been reported and will be reviewed under the respective sections for chemokine receptor antagonists and integrase inhibitors.

Rilpivirine (TMC278): Limited information exists on drug-drug interactions between rilpivirine and other antiretrovirals. Rilpivirine $\left(150 \mathrm{mg}\right.$ daily) increases the $C_{\max }, C_{\min }$, and AUC of tenofovir (300 mg daily) by $21-24 \%$ but is not thought to be clinically significant [59]. Darunavir/ritonavir (800 mg/100 mg daily) increased rilpivirine AUC and $\mathrm{C}_{\min }$ by $230-280 \%$ in healthy subjects; no change in darunavir or ritonavir pharmacokinetics was noted [60]. Rilpivirine pharmacokinetics are similarly increased by lopinavir/ritonavir ( $400 \mathrm{mg} / 100 \mathrm{mg}$ twice daily) where rilpivirine AUC and $C_{\min }$ are modestly elevated by $52 \%$ and $74 \%$, respectively [61]. The manufacturer states that rilpivirine dose modification is not necessary when rilpivirine is used at standards doses (25 mg daily) with either darunavir/ritonavir or lopinavir/ritonavir [62]. Coadministration of rilpivirine with other NNRTIs should be avoided due to the unfavorable interaction potential and cross-resistance concerns. Further studies are needed to ascertain the significance of interactions between rilpivirine and other antiretrovirals. 


\subsection{CCR5 Receptor Antagonists}

Maraviroc: Maraviroc is presently the only CCR5 receptor antagonist approved for use. The bioavailability of maraviroc is reduced by $33 \%$ with a high-fat meal and by $20 \%$ with a low-fat meal; however, no food restrictions are recommended by the manufacturer $[63,64]$. While maraviroc demonstrates little potential to alter the metabolism of other drugs, interaction with NNRTIs and protease inhibitors is likely due to shared metabolism through CYP3A4 and altered $p$-glycoprotein function [36]. Efavirenz (600 mg daily) reduces the maraviroc AUC in healthy volunteers and HIV-infected subjects by $51 \%$ and 53\%, respectively) [65,66]. Maraviroc $200 \mathrm{mg}$ twice daily with efavirenz produced a maraviroc AUC comparable to maraviroc $100 \mathrm{mg}$ twice daily [65]. Maraviroc systemic exposure is reduced by $53 \%$ with etravirine [67]. No significant change in maraviroc AUC from historical controls was noted when single-dose maraviroc (300 mg) was combined with nevirapine (200 mg twice daily) in HIV-infected subjects [66]. Coadministration of maraviroc (300 $\mathrm{mg}$ twice daily) with the protease inhibitor lopinavir/ritonavir (400 mg/100 mg twice daily) in healthy volunteers increased maraviroc AUC and $C_{\max }$ by approximately 4-fold and 2-fold, respectively [65]. Similar changes were observed in HIV-infected subjects [66]. Administration of maraviroc (100 mg twice daily) with saquinavir/ritonavir (1000 mg/100 mg twice daily) in healthy subjects increased maraviroc AUC and $C_{\max }$ by 9.8-fold and 4.8-fold, respectively [65]. Inclusion of efavirenz with either lopinavir/ritonavir or saquinavir/ritonavir yielded sustained increases in maraviroc AUC (2.5-fold and 5-fold, respectively) [65]. Maraviroc (300 mg twice daily) with either atazanavir (400 mg daily) or atazanavir/ritonavir $(300 \mathrm{mg} / 100 \mathrm{mg}$ daily) in healthy subjects resulted in increased maraviroc exposure (3.6-fold and 4.9-fold, respectively) [68]. In contrast, administration of maraviroc (150 $\mathrm{mg}$ twice daily) with tipranavir/ritonavir ( $500 \mathrm{mg} / 200 \mathrm{mg}$ twice daily) produced no clinically significant change in maraviroc serum concentrations (GMRs of 1.02 and 0.86 for maraviroc AUC or $C_{\max }$, respectively) [68].

When maraviroc (150 mg twice daily) was combined with the integrase inhibitor elvitegravir (150 mg daily) and ritonavir (100 mg daily) in healthy volunteers, the GMR for maraviroc AUC was 2.86 [69]. A 37\% and 28\% reduction in raltegravir AUC and $C_{\min }$, respectively, was observed when raltegravir (400 mg twice daily) and maraviroc (300 mg twice daily) were combined in healthy volunteers, but the clinical significance of this is presently unknown due to the wide variability in raltegravir pharmacokinetics [70]. Minor reductions in maraviroc AUC and $C_{\min }(10-14 \%)$ were also observed but are not considered clinically significant.

The dose-limiting side effect for maraviroc is orthostatic hypotension; therefore, maraviroc dose reduction is necessary when combined with strong CYP450 inhibitors [63]. The manufacturer of maraviroc recommends that the dose of maraviroc be reduced to $150 \mathrm{mg}$ twice daily with concomitant administration of the protease inhibitors lopinavir/ritonavir, saquinavir, atazanavir, or other strong CYP3A inhibitors [64]. This dose reduction should be employed irrespective of the inclusion of CYP3A inducers (e.g., etravirine, efavirenz) in the antiretroviral regimen. In contrast, the dose of maraviroc is recommended to be increased to $600 \mathrm{mg}$ twice daily with coadministration of strong CYP3A inducers (e.g., efavirenz, etravirine) in the absence of strong CYP3A inhibitors. No adjustment in the dose of maraviroc (300 $\mathrm{mg}$ twice daily) is recommended when coadministered with tipranavir/ritonavir, nevirapine, raltegravir, or NRTIs [64]. 


\subsection{Integrase Strand Transfer Inhibitors}

Raltegravir is the only integrase inhibitor presently approved for treatment of HIV infection. Elvitegravir (GS-9137) is an investigational integrase inhibitor that is being evaluated in Phase III trials and is expected to receive approval for marketing in late 2011. Dolutegravir (S/GSK 1349572) is another investigational integrase inhibitor in earlier clinical development that demonstrates activity against raltegravir- and elvitegravir-resistant viruses [71]. Important differences exist in the interaction potential between these agents.

Raltegravir: Interactions between raltegravir and other antiretrovirals are less common because raltegravir is primarily metabolized by UGT1A1 [72]. Interaction between raltegravir and atazanavir with or without ritonavir has been evaluated because of the well-established inhibitory effects of atazanavir on UGT1A1 [73]. Unboosted and boosted atazanavir increase raltegravir AUC by 45-75\% in healthy volunteers, but the magnitude of change is not thought to be clinically significant [74]. Similar increases in raltegravir AUC were observed with atazanavir coadministration in HIV-infected subjects [75]. The GMRs for raltegravir AUC and $C_{\min }$ are 0.76 and 0.46 , respectively, when tipranavir/ritonavir (500 mg/200 $\mathrm{mg}$ twice daily) and raltegravir (400 $\mathrm{mg}$ twice daily) are used concurrently in healthy volunteers, but the reduction in raltegravir serum concentrations is not thought to be clinically significant due to favorable viral suppression (55\% of patients [54/98] with HIV RNA $<50$ copies $/ \mathrm{mL}$ ) during phase III studies where the combination was used [76,77]. Etravirine decreased mean raltegravir $C_{\min }$ by $34 \%$ in healthy volunteers [78]. Concurrent use of raltegravir and etravirine was associated with incomplete viral suppression in a small case series $(n=4)$ of HIV-infected patients, but no clinically significant interaction was noted when etravirine and raltegravir were combined with darunavir/ritonavir [79,80]. Modest reduction $(28 \%)$ in raltegravir $C_{\min }$ was observed with maraviroc in healthy volunteers but was not considered to be clinically significant [70]. An increase in AUC and $C_{\min }(19 \%$ and $750 \%$, respectively) is observed when raltegravir is administered with a high-fat meal; however, raltegravir may be administered with or without food $[33,81]$.

Elvitegravir (GS-9137): Elvitegravir is metabolized by CYP3A4 and UGT1A1/UGT1A3 and requires use of a "boosting" agent to optimize its pharmacokinetic profile [82]. Bioavailability is increased approximately 3-fold when administered with food [83]. Coadministration with ritonavir or the novel investigational agent, cobicistat, prolongs systemic exposure, allowing once-daily dosing, and broadens the potential for drug-drug interactions. While the drug interaction profile of elvitegravir remains to be fully characterized, preliminary studies demonstrate no clinically significant interaction with planned co-formulated NRTIs, tenofovir disoproxil fumarate and emtricitabine, or with other NRTIs [84,85]. Similarly, no clinically relevant interaction was noted when elvitegravir was coadministered with tipranavir/ritonavir, darunavir/ritonavir, fosamprenavir/ritonavir, or etravirine [86-88]. Administration of elvitegravir (125 mg daily) with lopinavir/ritonavir (400 mg/100 mg twice daily) in HIV-infected subjects increased the elvitegravir AUC by $75 \%$; pharmacokinetic simulations suggest that the elvitegravir dose should be decreased to $85 \mathrm{mg}$ daily when used with lopinavir/ritonavir [89]. Coadministration of atazanavir/ritonavir (300 mg/100 mg daily) with elvitegravir (85 mg daily) in HIV-infected subjects produced elvitegravir systemic exposures 
comparable to elvitegravir/ritonavir $150 \mathrm{mg} / 100 \mathrm{mg}$ daily [90]. Administration of elvitegravir (300 mg daily) and unboosted atazanavir (400 $\mathrm{mg}$ daily) produces similar systemic exposure to elvitegravir/ritonavir (300 mg/100 mg daily), presumably due to impaired CYP3A4 metabolism by atazanavir; however, atazanavir AUC and $C_{\min }$ were lower (30\% and $46 \%$, respectively) compared with historical controls [91]. Dosage reduction for maraviroc (150 $\mathrm{mg}$ twice daily) is recommended when used in combination with elvitegravir due to the concomitant effect of the boosting agent (i.e., ritonavir, cobicistat) [69].

Dolutegravir (S/GSK 1349572): Dolutegravir is a substrate for UGT1A1 and CYP3A4 (10-15\%) and exhibits weak inhibitory potential for these isoenzymes based on preliminary findings [35,92]. Administration with food results in modest increases in systemic exposure depending on fat content (33\% with $300 \mathrm{kcal}, 7 \%$ fat; $41 \%$ with $600 \mathrm{kcal}, 30 \%$ fat; and $66 \%$ with $870 \mathrm{kcal}$, 53\% fat, respectively) but is not considered to be clinically significant [93]. Lopinavir/ritonavir coadministration (400 mg/100 mg twice daily) resulted in no change in dolutegravir pharmacokinetics in healthy volunteers; whereas, darunavir/ritonavir $(600 \mathrm{mg} / 100 \mathrm{mg}$ twice daily) decreased dolutegravir AUC and $C_{\min }$ by $22 \%$ and $38 \%$, respectively [92]. Tipranavir/ritonavir $(500 \mathrm{mg} / 200 \mathrm{mg}$ twice daily) decreases dolutegravir AUC by $59 \%$ and $C_{\min }$ by $76 \%$ in healthy volunteers [94]. No dose modification for dolutegravir is considered necessary for integrase inhibitor-naïve patients when given with darunavir/ritonavir or tipranavir/ritonavir [92,94]. Administration of atazanavir (400 mg daily) or atazanavir/ritonavir (300 mg daily) with dolutegravir (30 $\mathrm{mg}$ daily) results in modest elevation of dolutegravir pharmacokinetics in healthy volunteers (AUC increased by $62-91 \%, C_{\min }$ increased by 90-121\%) but is considered safe [95]. Dolutegravir AUC and $C_{\min }$ are reduced $(57 \%$ and $75 \%$, respectively) when dolutegravir (50 $\mathrm{mg}$ daily) is given with efavirenz (600 $\mathrm{mg}$ daily) but concentrations remain 4-5-fold above the protein-adjusted $\mathrm{IC}_{50}$ for wild-type virus [94]. Etravirine (200 mg twice daily) significantly reduces the AUC (71\%) and $C_{\min }(88 \%)$ of dolutegravir (50 $\mathrm{mg}$ daily) in healthy volunteers and should not be coadministered unless lopinavir/ritonavir or darunavir/ritonavir are also included [96]. No interaction is evident between dolutegravir and tenofovir disoproxil fumarate [97]. The drug-drug interaction profile of dolutegravir with maraviroc and integrase inhibitors remains to be characterized.

\section{Antiretroviral-Non-Antiretroviral Interactions}

Drug-drug interactions between antiretrovirals and medications for other co-morbidities are common and require an understanding by clinicians of which drug classes are prone to clinicallysignificant interactions. A comprehensive review of interactions between antiretrovirals and other medications is beyond the scope of this article; however, a summary of the interaction potential for medications widely used by clinicians for common co-morbidities is briefly discussed.

\subsection{Acid Suppressants}

Interactions between antiretrovirals and acid suppressants have been reported and occur as a result of complexation reactions, altered gastric $\mathrm{pH}$, or altered CYP metabolism. Complexation reactions can occur between antacids and integrase inhibitors, resulting in decreased oral bioavailability. Integrase 
inhibitors function as heavy metal chelators and bind to metallic ions in the HIV integrase enzyme active site [98]. Administration of aluminum, magnesium, or calcium-containing antacids can potentially serve as binding targets for integrase inhibitors. In one clinical study, it was noted that raltegravir $C_{\min }$ was decreased by $67 \%$ when simultaneously coadministered with an aluminum, magnesium, and simethicone-containing antacid [99]. Coadministration of elvitegravir with an antacid led to a $41 \%$ reduction in $C_{\min }$ when administered simultaneously and $10-20 \%$ when separated by two hours; no interaction was evident when separated by four hours [100]. Dolutegravir AUC was reduced by $74 \%$ with simultaneous administration of an aluminum, magnesium, and simethicone-containing antacid and 26\% when separated by 2 hours [101]. While the clinical significance of the serum concentration reductions in these studies is presently unknown, clinicians should advise patients to separate coadministration of antacids and integrase inhibitors by a minimum of two hours and preferably by four hours to minimize the potential for interaction. Given the potential for integrase inhibitors to bind to heavy metals, this recommendation should be applied to administration with vitamin and mineral supplements (e.g., zinc, iron). Administration of dolutegravir with a multivitamin resulted in a 33\% reduction in dolutegravir AUC [101]. Impairment of absorption of other antiretrovirals can also occur with antacids. Tipranavir $C_{\min }$ is reduced by $29 \%$ when tipranavir/ritonavir is administered concurrently with an aluminum and magnesium-containing antacid; therefore, tipranavir/ritonavir administration should be separated from antacids by at least two hours [102].

Alteration in gastric $\mathrm{pH}$ can also contribute to decreased absorption of antiretrovirals. The bioavailability of atazanavir, rilpivirine, and unboosted fosamprenavir and indinavir is reduced at elevated gastric $\mathrm{pH}$ [103-106]. In general, chronic use of acid suppressants should be avoided in patients receiving these agents. Detailed recommendations for atazanavir use with $\mathrm{H}_{2}$ receptor antagonists and proton pump inhibitors in antiretroviral treatment-naïve and treatment-experienced patients are provided by the manufacturer when coadministration is necessary and are included in Table 2. Rilpivirine bioavailability was reduced by $76 \%$ when famotidine was administered two hours before rilpivirine, but no change was observed when famotidine was administered four hours after or twelve hours before rilpivirine [106]. Administration of rilpivirine with proton pump inhibitors is not recommended [107]. Fosamprenavir should be given at least two hours before $\mathrm{H}_{2}$ receptor antagonists or boosted with low-dose ritonavir; interactions between fosamprenavir and proton pump inhibitors do not appear to be clinically significant when administered simultaneously [103,108,109]. Indinavir systemic exposure was decreased by $34-47 \%$ when indinavir $(800 \mathrm{mg}$ ) was administered as a single dose with omeprazole $(20-40 \mathrm{mg})$ in healthy volunteer, but this effect was nullified with the addition of ritonavir (200 mg) [110]. Raltegravir AUC and $C_{\max }$ are increased up to 3-4-fold when administered two hours after omeprazole in healthy volunteers, presumably due to enhancement of raltegravir bioavailability at higher gastric $\mathrm{pH}$ [111]. Modest increases in raltegravir pharmacokinetics are also observed with omeprazole and famotidine in HIV-infected subjects but are not considered clinically significant [111,112].

Potential metabolic interactions between antiretrovirals and the proton pump inhibitors have also been reported. Tipranavir/ritonavir reduces omeprazole AUC, presumably due to induction of CYP2C19, and may require titration of the omeprazole dose to achieve desired therapeutic end points [113]. Viral rebound has been reported in $51 \%$ of patients receiving proton pump inhibitors in 
combination with nelfinavir for greater than 30 days [114]. Nelfinavir forms an active metabolite (M8) through CYP2C19. Omeprazole is known to be a competitive inhibitor of CYP2C19 and has been associated with a $92 \%$ reduction in the M8 metabolite [115]. Use of proton pump inhibitors and nelfinavir together should be avoided.

\subsection{Antifungals}

Metabolic interactions between azole antifungals and antiretrovirals are likely to occur due to shared metabolism through CYP3A4 and the effects of various antiretrovirals on CYP2C9/19. Protease inhibitors can increase itraconazole and ketoconazole AUC by 2-3.4-fold and may require limiting doses to $200 \mathrm{mg} /$ day in some instances to minimize risk for adverse events [116-120]. Voriconazole serum concentrations are decreased (39\%) when combined with low-dose ritonavir (100 mg BID); therefore, the manufacturer for voriconazole recommends that administration with boosted protease inhibitors should be avoided unless the benefit outweighs the risk [121]. Reduction in itraconazole, ketoconazole, and voriconazole systemic exposures can be expected with NNRTIs (except for delavirdine and etravirine-voriconazole) and may require azole dose adjustment to maintain therapeutic concentrations or alteration of antiretroviral therapy [29,109,122-126]. Posaconazole is less prone to interactions with antiretrovirals than older azoles because of its principal metabolism by UGT; however, lower posaconazole serum concentrations have been reported with efavirenz coadministration [127]. The pharmacokinetics of fluconazole are not significantly altered by antiretrovirals [29,128-130]. Among the echinocandins, caspofungin serum concentrations are decreased (20-40\%) when caspofungin is used with strong inducers, including efavirenz and nevirapine, and may require empiric dose adjustment to maintain therapeutic concentrations [131]. Clinically significant interactions between antiretrovirals and other echinocandins (micafungin, anidulafungin) have not been described. An overview of common interactions between antifungals and antiretrovirals are summarized in Table 2.

\subsection{Antilipidemics}

HMG CoA reductase inhibitors (statins) are prone to interaction with antiretrovirals as a result of metabolism through CYP3A4 and CYP2C19 and inhibition of hepatic uptake by the OATP1B1 transporter [2,109]. Protease inhibitors can induce dyslipidemia or augment existing dyslipidemia, resulting in the need for antilipidemic therapy [132]. Statins are preferred agents for dyslipidemia because of their proven benefit on cardiovascular morbidity and mortality. Substantial increases in systemic exposure for various statins have been observed when administered with protease inhibitors. Coadministration of simvastatin (40 mg daily) with saquinavir/ritonavir (400 mg/400 mg twice daily) results in a 30-fold increase in simvastatin AUC [133]. Lovastatin is expected to exhibit significant increases in systemic exposure because of its reliance on CYP3A4-medicated metabolism [109]. A modest increase in rosuvastatin and atorvastatin AUCs is also observed when given with protease inhibitors (1.5-2-fold and 3.4-5-fold, respectively), but these agents are generally considered to be safe for use when initiated at low doses [132-136]. An exception is the use of rosuvastatin and lopinavir/ritonavir, where increases in rosuvastatin systemic exposure were associated with creatine kinase and transaminase elevations in healthy volunteers [137]. Preliminary findings with pitavastatin 
and several protease inhibitors (atazanavir, lopinavir/ritonavir) demonstrate no clinically significant interactions, making pitavastatin a potential alternative to atorvastatin and rosuvastatin $[138,139]$. Fluvastatin and pravastatin appear to be less prone to metabolic inhibition with protease inhibitors as a result of metabolism through other metabolic pathways and may also be suitable for use [132]. Titration to higher doses of statins may be necessary in individual patients receiving NNRTIs (except delavirdine) to achieve desired lipid targets because of induction of CYP3A4 [140].

\subsection{Miscellaneous Medications}

A variety of other medications commonly used in primary care settings can exhibit altered metabolism when used with antiretrovirals. In many instances, these interactions have not been formally evaluated but have been identified through case reports in the literature.

Administration of boosted PIs with levothyroxine can lead to hypothyroidism, presumably due to induction of UGT1A1 by ritonavir [141]. Atazanavir and indinavir are exceptions, where inhibition of UGT1A1 by these two agents is likely to predominate, leading to hyperthyroidism [18,142]. Chronic administration of inhaled or intranasal fluticasone with protease inhibitors is associated with development of iatrogenic Cushing syndrome [143,144]. Subsequent study has demonstrated that fluticasone serum concentrations are increased by 350-fold when given with low-dose ritonavir, likely due to impairment of CYP3A4 metabolism [145]. Elevation of other corticosteroids (e.g., budesonide, prednisolone) has also been reported with ritonavir coadministration [146,147]. Similarly, salmeterol serum concentrations can be increased by boosted and unboosted protease inhibitors, increasing the risk for cardiac arrhythmias, and should not be coadministered [148]. Warfarin metabolism can be altered by a variety of antiretrovirals due to inhibition or induction of CYP2C9; a summary of specific interactions between antiretrovirals and warfarin is included in Table 2 [13]. The erectile dysfunction agents (sildenafil, taladafil, vardenafil) all exhibit significant potential for interaction with antiretrovirals metabolized by CYP3A4 and require dosage adjustment when beginning therapy to minimize the risk for symptomatic hypotension and priapism [109]. The interaction potential and clinical management of antiretrovirals with anticonvulsants and antimycobacterials are reviewed in Table 2. 
Table 2. Select antiretroviral drug interactions with medications for other comorbidities.

\begin{tabular}{|c|c|c|c|}
\hline Medication & Antiretroviral & Predicted Effect & Management \\
\hline \multicolumn{4}{|c|}{ Acid-Suppressants $[106,107,109,110,115,149]$} \\
\hline Antacids & $\begin{array}{l}\text { Integrase Inhibitors } \\
\text { Atazanavir } \pm \text { ritonavir } \\
\text { Fosamprenavir (unboosted) } \\
\text { Tipranavir/ritonavir }\end{array}$ & 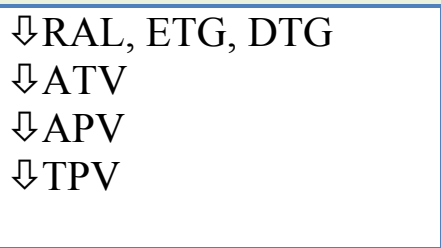 & $\begin{array}{l}\text { - } \quad \text { Consider separating administration by } 4 \text { hours. } \\
\text { - Take ATV } 2 \text { hours before or } 1 \text { hour after antacids } \\
\text { - Take FPV simultaneously or } 2 \text { hours before or } 1 \text { hour after } \\
\text { antacids } \\
\text { - Take TPV } 2 \text { hours before or } 1 \text { hour after antacids }\end{array}$ \\
\hline $\begin{array}{l}\mathrm{H}_{2} \text {-Receptor } \\
\text { Antagonists } \\
(\mathrm{H} 2 \mathrm{~A})\end{array}$ & $\begin{array}{l}\text { Atazanavir/ritonavir } \\
\text { Atazanavir (unboosted) } \\
\text { Fosamprenavir (unboosted) } \\
\text { Rilpivirine }\end{array}$ & 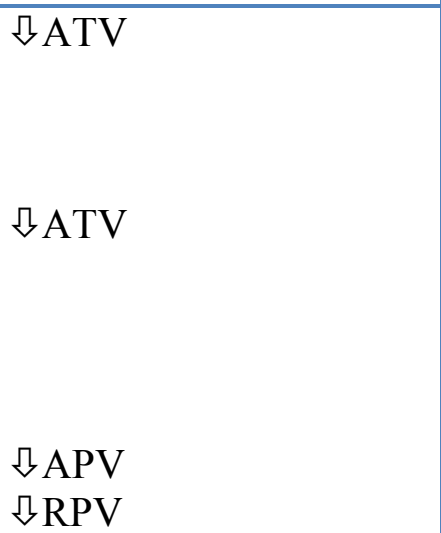 & $\begin{array}{l}\text { Administer boosted ATV simultaneously or } \geq 10 \text { hours after } \\
\text { H2A; do not exceed } 40 \mathrm{mg} \text { famotidine dose equivalent BID } \\
\text { (ART-naïve) or } 20 \mathrm{mg} \text { dose equivalent BID (ART- } \\
\text { experienced). For TDF-containing ART (ART-experienced), } \\
\text { use ATV } 400 \mathrm{mg}+\text { RTV } 100 \mathrm{mg} \text {. } \\
\text { Administer unboosted ATV } 2 \text { hours before or } \geq 10 \text { hours after } \\
\text { H2A; do not exceed dose equivalent of famotidine } 20 \mathrm{mg} \text { as a } \\
\text { single dose or } 20 \mathrm{mg} \text { BID total daily dose (ART-naïve). Avoid } \\
\text { coadministration in ART-experienced patients. } \\
\text { - Take FPV } \geq 2 \text { hours before H2A; consider ritonavir boosting. } \\
\text { - Administer H2A either } 12 \text { hours before or } 4 \text { hours after RPV. }\end{array}$ \\
\hline $\begin{array}{l}\text { Proton Pump } \\
\text { Inhibitors } \\
\text { (PPIs) }\end{array}$ & $\begin{array}{l}\text { Indinavir (unboosted) } \\
\text { Nelfinavir } \\
\text { Saquinavir/ritonavir } \\
\text { Tipranavir/ritonavir } \\
\text { Rilpivirine }\end{array}$ & 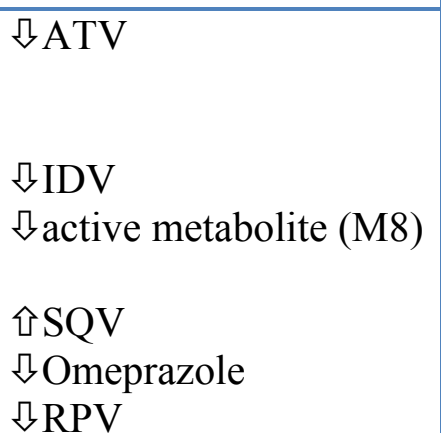 & $\begin{array}{l}\text { PPIs not recommended with unboosted ATV or in ART- } \\
\text { experienced patients. Do not exceed omeprazole } 20 \mathrm{mg} \text { dose } \\
\text { equivalent; separate dosing by } \geq 12 \text { hours (ART-naïve) } \\
\text { - } \text { Avoid coadministration; consider ritonavir boosting } \\
\text { - Avoid coadministration (decreased active metabolite } \\
\text { formation) } \\
\text { - } \text { Monitor for SQV-related adverse effects } \\
\text { - Consider omeprazole dose increase. } \\
\text { - } \text { Do not coadminister with proton pump inhibitors }\end{array}$ \\
\hline
\end{tabular}


Table 2. Cont.

\begin{tabular}{|c|c|c|c|}
\hline \multicolumn{4}{|c|}{ Anticoagulants $[13,109]$} \\
\hline Clopidogrel & Etravirine & $\begin{array}{l}\text { Jclopidogrel active } \\
\text { metabolite }\end{array}$ & $\begin{array}{l}\text { - Avoid coadministration (potential for decreased clopidogrel } \\
\text { active metabolite formation) }\end{array}$ \\
\hline Warfarin & $\begin{array}{l}\text { Boosted PIs, Nelfinavir } \\
\text { Unboosted PIs (except NFV) } \\
\text { Efavirenz, Etravirine, Delavirdine } \\
\text { Nevirapine }\end{array}$ & $\begin{array}{l}\text { 』Warfarin } \\
\text { 仓/』Warfarin } \\
\text { 仓Warfarin } \\
\text { 』Warfarin }\end{array}$ & $\begin{array}{l}\text { - } \quad \text { Adjust warfarin dose accordingly based on INR. } \\
\text { - } \quad \text { Adjust warfarin dose accordingly based on INR. } \\
\text { - } \\
\text { - }\end{array}$ \\
\hline \multicolumn{4}{|c|}{ Anticonvulsants $[109,150]$} \\
\hline $\begin{array}{l}\text { Carbamazepine } \\
\text { (CBZ) }\end{array}$ & $\begin{array}{l}\text { Boosted PIs (except DRV) } \\
\text { Darunavir/ritonavir } \\
\text { Atazanavir, Fosamprenavir } \\
\text { (unboosted) } \\
\text { Efavirenz }\end{array}$ & $\begin{array}{l}\curvearrowleft \mathrm{PI}, \text { 仓 } \mathrm{CBZ} \\
\text { 仓CBZ } \\
\curvearrowleft \mathrm{PI} \\
\curvearrowleft \mathrm{EFV}, \curvearrowleft \mathrm{CBZ}\end{array}$ & $\begin{array}{l}\text { - Monitor carbamazepine serum concentrations and HIV viral } \\
\text { load; do not coadminister with LPV/r once-daily. } \\
\text { - Monitor carbamazepine serum concentrations } \\
\text { - Monitor carbamazepine serum concentrations and HIV viral } \\
\text { load; consider ritonavir boosting } \\
\text { - Monitor carbamazepine serum concentrations and HIV viral } \\
\text { load }\end{array}$ \\
\hline Lamotrigine & Boosted PIs & $\sqrt{2} \mathrm{LMG}$ & - Monitor lamotrigine serum concentrations \\
\hline $\begin{array}{l}\text { Phenytoin } \\
\text { (PHT) }\end{array}$ & $\begin{array}{l}\text { Boosted PIs } \\
\text { Atazanavir, Fosamprenavir } \\
\text { (unboosted) } \\
\text { Efavirenz, Etravirine } \\
\text { Maraviroc }\end{array}$ & 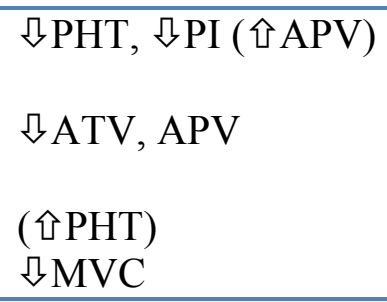 & $\begin{array}{l}\text { - Monitor phenytoin serum concentrations and HIV viral load; } \\
\text { do not coadminister with LPV/r once-daily. } \\
\text { - Monitor phenytoin serum concentrations and HIV viral load; } \\
\text { consider ritonavir boosting } \\
\text { - Monitor phenytoin serum concentrations and HIV viral load. } \\
\text { - Increase MVC dose to } 600 \mathrm{mg} \text { BID. }\end{array}$ \\
\hline $\begin{array}{l}\text { Valproic Acid } \\
\text { (VPA) }\end{array}$ & $\begin{array}{l}\text { Lopinavir/ritonavir } \\
\text { Zidovudine }\end{array}$ & $\begin{array}{l}\text { そVPA, 仓 } \mathrm{LPV} \\
\text { 仓ZDV }\end{array}$ & $\begin{array}{l}\text { Monitor valproic acid serum concentrations and response; } \\
\text { monitor for LPV toxicity } \\
\text { - Monitor for ZDV-related adverse events }\end{array}$ \\
\hline
\end{tabular}


Table 2. Cont.

\begin{tabular}{|c|c|c|c|}
\hline \multicolumn{4}{|c|}{ Corticosteroids $[109,151]$} \\
\hline Dexamethasone & PIs & nPIs & - Use with caution; consider alternative corticosteroid \\
\hline Budesonide & Boosted PIs & 仓Budesonide & $\begin{array}{l}\text { - Avoid chronic coadministration unless potential benefit outweighs risk for } \\
\text { systemic corticosteroid adverse effects }\end{array}$ \\
\hline $\begin{array}{l}\text { Fluticasone } \\
\text { (inhaled/intranasal) }\end{array}$ & PIs, Delavirdine & 仓Fluticasone & $\begin{array}{l}\text { - Avoid chronic coadministration unless potential benefit outweighs risk for } \\
\text { systemic corticosteroid adverse effects }\end{array}$ \\
\hline Prednisone & Boosted PIs & 仓Prednisolone & $\begin{array}{l}\text { Avoid chronic coadministration unless potential benefit outweighs risk for } \\
\text { systemic corticosteroid adverse effects }\end{array}$ \\
\hline Triamcinolone & Boosted PIs & 仓Prednisolone & $\begin{array}{l}\text { - Avoid chronic coadministration unless potential benefit outweighs risk for } \\
\text { systemic corticosteroid adverse effects }\end{array}$ \\
\hline \multicolumn{4}{|c|}{ Antifungals $[68,109,113,123-126,131,152]$} \\
\hline Fluconazole & $\begin{array}{l}\text { Tipranavir/ritonavir } \\
\text { Etravirine, Nevirapine }\end{array}$ & $\begin{array}{l}\text { 仓TPV/r } \\
\text { 仓िTV, NVP }\end{array}$ & $\begin{array}{l}\text { - Fluconazole doses }>200 \mathrm{mg} / \mathrm{d} \text { not recommended; consider alternative PI or } \\
\text { another antiretroviral class } \\
\text { - Monitor for ETV- and NVP-related adverse events }\end{array}$ \\
\hline Itraconazole & $\begin{array}{l}\text { PIs } \\
\text { NNRTIs (except DLV) } \\
\text { Maraviroc }\end{array}$ & $\begin{array}{l}\text { (仓ITZ, 仓PI) } \\
\text { nITZ, 仓ETV, NVP } \\
\text { (仓MVC) }\end{array}$ & $\begin{array}{l}\text { - Consider monitoring itraconazole serum concentrations or not exceeding } \\
\text { itraconazole } 200 \mathrm{mg} / \text { day } \\
\text { - Monitor itraconazole serum concentrations and antifungal response } \\
\text { - Decrease MVC dose to } 150 \mathrm{mg} \text { BID. }\end{array}$ \\
\hline Posaconazole & $\begin{array}{l}\text { Atazanavir } \pm \text { ritonavir } \\
\text { Efavirenz }\end{array}$ & $\begin{array}{l}\text { 仓ATV } \\
\text { §PCZ }\end{array}$ & $\begin{array}{l}\text { - Monitor for ATV-related adverse events } \\
\text { Consider alternative antifungal or monitoring posaconazole serum } \\
\text { concentrations }\end{array}$ \\
\hline Voriconazole & $\begin{array}{l}\text { Boosted PIs } \\
\text { Efavirenz } \\
\text { Nevirapine, Rilpivirine }\end{array}$ & 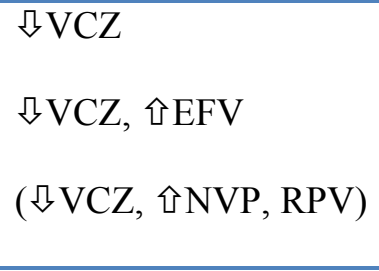 & $\begin{array}{l}\text { - Avoid coadministrationr with boosted PIs; consider monitoring voriconazole } \\
\text { serum concentrations } \\
\text { - Increase voriconazole maintenance dose to } 400 \mathrm{mg} \text { BID and decrease EFV } \\
\text { by } 50 \% \\
\text { - Monitor for NNRTI-related adverse effects, antifungal response and/or } \\
\text { voriconazole serum concentrations }\end{array}$ \\
\hline Ketoconazole & $\begin{array}{l}\text { PIs } \\
\text { Efavirenz, Nevirapine } \\
\text { Etravirine, Rilpivirine } \\
\text { Maraviroc }\end{array}$ & 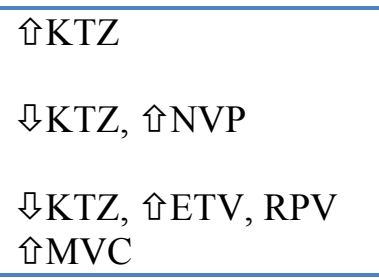 & $\begin{array}{l}\text { - Monitor for ketoconazole-related adverse effects; consider not exceeding } \\
\text { ketoconazole } 200 \mathrm{mg} / \text { day } \\
\text { - Avoid coadministration; monitor antifungal response and/or ketoconazole } \\
\text { serum concentrations } \\
\text { - } \quad \text { Monitor for antifungal response and ETV- and RPV-related adverse events. } \\
\text { - Decrease MVC dose to } 150 \mathrm{mg} \text { BID. }\end{array}$ \\
\hline Caspofungin & Efavirenz, Nevirapine & $\sqrt{ }$ Caspofungin & - Consider increasing caspofungin dose to $70 \mathrm{mg}$ \\
\hline
\end{tabular}


Table 2. Cont.

\begin{tabular}{|c|c|c|c|}
\hline \multicolumn{4}{|c|}{ Antilipidemics [109,137-139] } \\
\hline $\begin{array}{l}\text { Statins } \\
\text { (Simvastatin, } \\
\text { Lovastatin) }\end{array}$ & $\begin{array}{l}\text { Efavirenz, Etravirine, } \\
\text { Nevirapine }\end{array}$ & $\llbracket$ Statin & $\begin{array}{l}\text { Do not coadminister due to increased risk for serious adverse events; } \\
\text { consider atorvastatin, rosuvastatin, pitavastatin, fluvastatin, pravastatin as } \\
\text { alternatives beginning at low doses } \\
\text { Titration of statin dose may be necessary to achieve desired treatment } \\
\text { response. }\end{array}$ \\
\hline Rosuvastatin & Lopinavir/ritonavir & 仓Rosuvastatin & - Use with caution (increased risk for serious adverse events) \\
\hline \multicolumn{4}{|c|}{ Antimycobacterials $[109,153-156]$} \\
\hline Clarithromycin & $\begin{array}{l}\text { Atazanavir } \pm \text { ritonavir } \\
\text { Boosted PIs (except ATV) } \\
\text { NNRTIs (except DLV) } \\
\text { Maraviroc }\end{array}$ & $\begin{array}{l}\text { 仓Clarithromycin } \\
\text { 仓Clarithromycin } \\
\text { 凤Clarithromycin } \\
\text { 仓MVC }\end{array}$ & $\begin{array}{l}\text { - Reduce clarithromycin dose by } 50 \% \text { due to risk for QTc prolongation } \\
\text { - Monitor for clarithromycin-related adverse effects; reduce clarithromycin } \\
\text { dose by } 50 \% \text { for patients with } \mathrm{CrCl} 30-60 \mathrm{~mL} / \mathrm{min} \text { and by } 75 \% \text { with } \mathrm{CrCl} \\
<30 \mathrm{~mL} / \mathrm{min} \\
\text { - Consider alternatives to clarithromycin } \\
\text { - } \quad \text { Decrease MVC dose to } 150 \mathrm{mg} \text { BID }\end{array}$ \\
\hline Rifampin & $\begin{array}{l}\text { PIs } \\
\text { Efavirenz } \\
\text { NNRTIs (except EFV) } \\
\text { Raltegravir } \\
\text { Maraviroc }\end{array}$ & 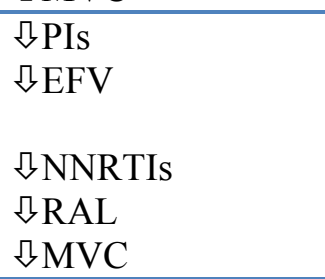 & 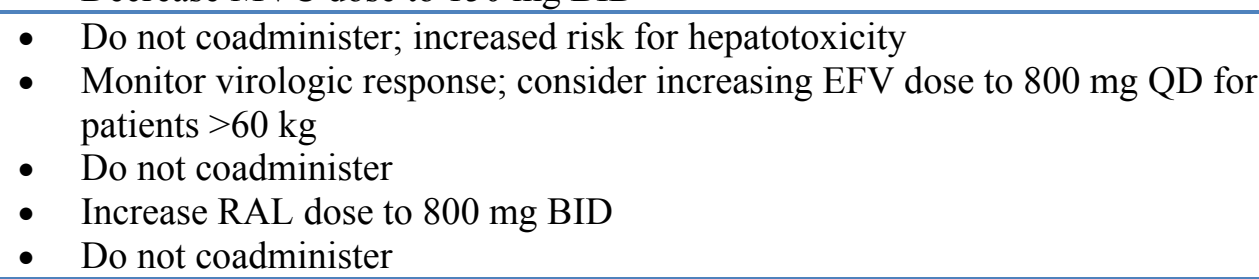 \\
\hline Rifabutin & $\begin{array}{l}\text { Boosted PIs, Atazanavir } \\
\text { (unboosted) } \\
\text { Fosamprenavir, Indinavir } \\
\text { (unboosted) } \\
\text { Efavirenz } \\
\text { Etravirine } \\
\text { Rilpivirine, Delavirdine }\end{array}$ & 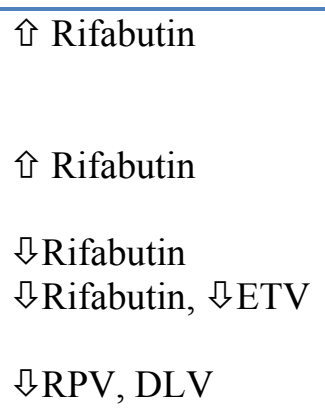 & $\begin{array}{l}\text { - Decrease rifabutin to } 150 \mathrm{mg} \text { QOD or 3x/week; some experts recommend } \\
150 \mathrm{mg} \text { QD or } 300 \mathrm{mg} 3 \mathrm{x} / \mathrm{week} \text { due to increased risk of treatment failure } \\
\text { with } 150 \mathrm{mg} 3 \mathrm{x} / \mathrm{week} \text { dosing. TDM for rifabutin recommended. } \\
\text { - Decrease rifabutin to } 150 \mathrm{mg} \text { QD or } 300 \mathrm{mg} 3 \mathrm{x} / \text { week; increase IDV to } 1000 \\
\text { mg q8 hours } \\
\text { - Increase rifabutin to } 450 \mathrm{mg} \text { daily } \\
\text { - Do not use rifabutin when ETV is combined with boosted PIs } \\
\text { - Do not coadminister }\end{array}$ \\
\hline
\end{tabular}


Table 2. Cont.

\begin{tabular}{|c|c|c|c|}
\hline \multicolumn{4}{|c|}{ Erectile Dysfunction Agents [109] } \\
\hline $\begin{array}{l}\text { PDE5 Inhibitors } \\
\text { (Sildenafil, } \\
\text { Tadalafil, } \\
\text { Vardenafil) }\end{array}$ & PIs, Delavirdine & 仓PDE5 Inhibitor & $\begin{array}{l}\text { - Begin with sildenafil } 25 \mathrm{mg} \text { Q48 hours. Begin with tadalafil } 5 \mathrm{mg} \text {; do not } \\
\text { exceed } 10 \mathrm{mg} \text { Q72 hours. Begin with vardenafil } 2.5 \mathrm{mg} \text {; do not exceed } 2.5 \\
\text { mg Q72 hours } \\
\text { - Increase in PDE5 inhibitor dose may be necessary }\end{array}$ \\
\hline \multicolumn{4}{|c|}{ Miscellaneous $[18,109,141,142]$} \\
\hline Levothyroxine & $\begin{array}{l}\text { Boosted PIs (except ATV, } \\
\text { IDV) } \\
\text { Atazanavir, Indinavir }\end{array}$ & $\begin{array}{l}\text { \Levothyroxine } \\
\text { 仓Levothyroxine }\end{array}$ & $\begin{array}{l}\text { - } \text { Monitor TSH and titrate levothyroxine dose accordingly } \\
\text { - } \\
\text { - Monitor TSH and titrate levothyroxine dose accordingly }\end{array}$ \\
\hline Salmeterol & PIs \pm ritonavir & 仓Salmeterol & - Do not coadminister due to increased risk for arrhythmias \\
\hline
\end{tabular}

$\mathrm{APV}=$ amprenavir, ART $=$ antiretroviral therapy, $\mathrm{ATV}=$ atazanavir, $\mathrm{CBZ}=$ carbamazepine, $\mathrm{DLV}=$ delavirdine, $\mathrm{DRV}=\mathrm{darunavir}$, $\mathrm{DTG}=$ dolutegravir, FPV = fosamprenavir, EFV = efavirenz, ETG = elvitegravir, ETV = etravirine, FLU = fluconazole, IDV = indinavir, $\mathrm{ITZ}=$ itraconazole, $\mathrm{KTZ}=$ ketoconazole, $\mathrm{LMG}=$ lamotrigine, $\mathrm{LPV}=$ lopinavir, $\mathrm{MVC}=$ maraviroc, NNRTIs $=$ non-nucleoside reversetranscriptase inhibitors, NVP = nevirapine, $\mathrm{PCZ}=$ posaconazole, $\mathrm{PDE} 5=$ phosphodiesterase -5 inhibitors, $\mathrm{PHT}=$ phenytoin, $\mathrm{PIs}=$ protease inhibitors, $\mathrm{RAL}=$ raltegravir, $\mathrm{RPV}=$ rilpivirine, $\mathrm{TPV}=$ tipranavir, $\mathrm{TSH}=$ thyroid stimulating hormone, $\mathrm{VCZ}=$ voriconazole . 


\section{Therapeutic Drug Monitoring to Manage Drug-Drug Interactions}

\subsection{Rationale for Therapeutic Drug Monitoring}

Therapeutic drug monitoring (TDM) is the practice of dosing medications in response to plasma drug concentrations with the goal of maintaining concentrations within a clinically determined therapeutic target range. The aim is to optimize the clinical efficacy of a medication while minimizing or eliminating its concentration-dependent toxicities. In order for TDM to be valuable, a relationship between plasma concentrations and efficacy and/or toxicity must be established with a therapeutic agent. The role of TDM in regard to antiretrovirals continues to be largely undefined. Various small prospective and retrospective studies have displayed benefits in achieving virologic outcomes and minimizing toxicity when TDM is used in routine practice [157-159]. However, experts agree that large, well-designed trials are still needed to clearly delineate the role of TDM and to identify which patients may benefit most from its use [160,161]. One of the proposed populations where TDM may be advantageous is for patients at risk for clinically significant drug interactions [160]. Given that patients receiving antiretrovirals may experience complex, often unpredictable interactions with concomitant medications, the use of TDM can potentially allow examination and correction of altered serum concentrations prior to the development of virologic failure or adverse events.

The rationale for TDM in patients treated with antiretrovirals is primarily based on the large interpatient variation in serum concentration that some agents exhibit when the same dose is administered to different patients $[157,162,163]$. This variation may be due to many factors including alteration in absorption, membrane transport, hepatic metabolism, and drug interactions. It follows that, if plasma drug concentrations can be reliably maintained within established ranges for efficacy and safety, clinicians can improve treatment response and limit toxicity risks for individual patients. Antiretroviral resistance development is associated with subtherapeutic drug levels and intermittent antiretroviral administration [164]. If clinicians are able to determine which patients are at risk for resistance development earlier in treatment (e.g., suboptimal drug concentrations due to erratic adherence from poor drug tolerability), dose alteration could potentially ameliorate drug intolerance and avoid the acquisition of antiretroviral resistance altogether. Another theoretical benefit of TDM is optimization of antiretroviral regimens in patients who have limited treatment options secondary to either extensive resistance or economic constraints. Adjusting doses to increase virologic suppression and limit toxicity might allow providers to use individual antiretrovirals longer without needing to change therapy.

The role of TDM for different antiretroviral classes varies. Protease inhibitors and NNRTIs display greater than 100-fold variation in pharmacokinetic parameters (AUC, $C_{\max }, C_{\min }$ ) associated with efficacy and toxicity end points $[157,162,163,165]$. This characteristic, combined with data supporting concentration-effect and concentration-toxicity relationships, makes protease inhibitors and NNRTIs the most likely candidates for TDM $[157,161,166]$. The CCR5 receptor antagonist, maraviroc, is a substrate for CYP3A4 and is highly susceptible to serum concentration changes when coadministered with strong CYP3A4 inducers or inhibitors. However, limited data exist on an observed association between maraviroc trough concentrations and virologic response to support it as a candidate for TDM [64,109,167]. The fusion inhibitor, enfuvirtide, and the integrase inhibitor, raltegravir, have relatively few drug interactions with other antiretrovirals or medications and do not utilize the CYP450 
system for metabolism; therefore, no compelling role for TDM exists for them [165]. The clinical effect of NRTIs is related to the intracellular concentration of their active triphosphate; therefore, plasma concentrations are less predictive of clinical response or toxicity [168]. These agents also are predominantly eliminated renally and, with the exception of tenofovir, exhibit minimal potential for metabolic interactions, making plasma concentration monitoring of limited utility for NRTIs in general.

\subsection{Barriers to Therapeutic Drug Monitoring}

Barriers to routine application of TDM in clinical practice remain fairly formidable. Significant debate continues about which pharmacokinetic parameter(s) provides the best measure for drug efficacy or toxicity. Researchers have used a combination of $C_{\min }, C_{\max }$, AUC, and concentration ratio to assess efficacy and toxicity outcomes [169]. At the present time, the $C_{\min }$ provides the best measure of virologic effect for most clinical scenarios without requiring complex calculations and population parameters [165]. However, definitive target values remain to be defined. Consensus guidelines have identified target trough concentrations for TDM in antiretroviral-naïve patients with wild-type virus; these values are listed in Table 3 [109,160,165,170]. It is not clear if individual targets are applicable to both antiretroviral-naïve and antiretroviral-experienced patients. In the case of antiretroviralexperienced patients, resistance mutations may increase the target antiretroviral serum concentration required to achieve viral suppression. Several studies have attempted to define the antiretroviral inhibitory quotient, which represents a combination of both pharmacokinetic/pharmacodynamic properties of the medication as well as virus-specific resistance information from either genotypic or phenotypic testing. Several different IQs have been proposed, with the PIQ (phenotype-based) and GIQ (genotype-based) discussed most predominately. The PIQ represents the ratio between the $C_{\min }$ and the $\mathrm{IC}_{50}$ or $\mathrm{IC}_{90}$ measured by phenotypic resistance testing. The GIQ is defined as the ratio between $C_{\min }$ and the number of resistance-associated mutations [161,165,169]. At the present time, no agreement exists on which inhibitory quotient is most closely tied to positive therapeutic outcomes. Preliminary target cutoffs have been proposed but require further study to correlate antiretroviral dose with viral response in patients with underlying resistance. It may be possible to overcome low- to midlevel resistance by utilizing IQ targets to individualize antiretroviral doses, giving clinicians an effective tool to achieve virologic success in highly treatment-experienced patients with numerous resistance mutations [161]. It is possible that targets will also vary based on the extent of synergy in individual antiretroviral combinations. Additionally, most protease inhibitors and NNRTIs are highly bound to plasma proteins; however, current targets are expressed as total plasma concentrations and do not correct for altered protein binding. 
Table 3. Minimum antiretroviral trough concentration targets for treatment-naïve and treatment-experienced patients [109].

\begin{tabular}{|c|c|c|}
\hline $\begin{array}{l}\text { Antiretroviral } \\
\text { Drug }\end{array}$ & $\begin{array}{c}\text { Minimum Trough Concentrations } \\
\text { (Treatment-Naïve Patients) } \\
{[\mathrm{ng} / \mathrm{mL}]}\end{array}$ & $\begin{array}{c}\text { Minimum Trough Concentrations } \\
\text { (Treatment-Experienced Patients) } \\
{[\mathrm{ng} / \mathrm{mL}]}\end{array}$ \\
\hline Atazanavir & 150 & \\
\hline Darunavir $^{\mathrm{a}}$ & & 3,300 \\
\hline Fosamprenavir & 400 & \\
\hline Indinavir & 100 & \\
\hline Lopinavir/ritonavir & 1,000 & \\
\hline Nelfinavir ${ }^{\mathrm{b}}$ & 800 & \\
\hline \multicolumn{3}{|l|}{ Ritonavir } \\
\hline Saquinavir & $100-250$ & \\
\hline Tipranavir & & 20,500 \\
\hline Efavirenz & 1,000 & \\
\hline Nevirapine & 3,000 & \\
\hline Etravirine $^{\mathrm{a}}$ & & 275 \\
\hline Maraviroc & & $>50$ \\
\hline Raltegravir $^{\mathrm{a}}$ & & 72 \\
\hline
\end{tabular}

${ }^{\text {a }}$ Target serum concentrations represent median trough concentrations from clinical trials;

${ }^{\mathrm{b}}$ Target serum concentrations represent the active metabolite (M8)

Laboratory validity is also a potential barrier to the clinical application of TDM results in different countries. Various methodologies can be employed by different clinical laboratories to measure antiretroviral plasma concentrations [160,171]. There is currently no standardized procedure or regulated quality control for determination of antiretroviral serum concentrations in laboratories in most commercial settings, making it difficult to apply specific laboratory results to proposed serum concentration targets established in research studies. Within the United States, the availability of reputable laboratories to perform antiretroviral serum concentration measurements is also limited, necessitating transport of patient samples that can extend turnaround time and decrease the clinical utility of laboratory results for patient management.

\subsection{Role of Therapeutic Drug Monitoring for Drug-Drug Interactions}

Despite the barriers that exist to widespread acceptance, clinical application of TDM has increased in the past few years, particularly in some European countries. In the United States, TDM continues to be primarily used in a research capacity. Treatment guidelines in several countries offer some limited information and guidance in the use of TDM [109,172-174]. There is uniform agreement between guidelines that routine application of TDM in patients treated with antiretrovirals is currently not recommended based on clinical evidence [109,169,172-174]. Most guidelines, including the United States Department of Health and Human Services Antiretroviral Treatment Guidelines [109], state that TDM may be useful in specific patient populations that could be at risk for subtherapeutic or supratherapeutic antiretroviral concentrations. One of the populations identified is patients with potential drug-drug interactions [109,161,169,172-174]. Two recent studies have investigated which patients may be at greater risk for experiencing drug-drug interactions. The factors identified include older patients ( $>42$ years old), presence of more than three co-morbid conditions, treatment with more than five non-antiretroviral agents, antiretroviral therapy consisting of more than three antiretroviral 
medications, and use of either a protease inhibitor- or NNRTI-containing regimen [175,176]. In patient populations such as these that may be at increased risk for clinically significant drug-drug interactions, TDM may be prudent at the initiation of therapy or with medication changes to assure successful attainment of treatment outcomes. In addition, TDM would be advised for any patients with a high potential for drug-drug interactions that are experiencing unexpected clinical outcomes (e.g., sluggish viral load response, excessive adverse events). Therapeutic drug monitoring may provide insight into the cumulative effect on individual drug concentrations for antiretroviral regimens that involve multiple drug-drug interactions and whether antiretroviral doses are appropriate to achieve desired therapeutic end points. Practitioners who wish to perform TDM should keep in mind the limitations discussed and utilize guideline targets if possible. Expert consultation is advised for management of complex cases where extensive antiretroviral drug resistance is involved.

\section{Conclusions}

Combination antiretroviral therapy is highly effective in reducing HIV-related morbidity and mortality; however, clinicians must balance treatment outcomes with the potential for complex drugdrug interactions between antiretroviral and with medications for other chronic diseases. Antiretrovirals are prone to drug-drug interactions as a result of shared metabolism through CYP450 and UGT isoforms and binding to membrane transporters. Protease inhibitors and NNRTIs, including the newer agents darunavir and etravirine, commonly alter the metabolism of other medications. The clinical significance of drug interactions between rilpivirine, the newest NNRTI, and other antiretrovirals remains to be determined. Maraviroc is the only CCR5 receptor antagonist presently available and frequently requires dose modification with other antiretrovirals. The integrase inhibitor, raltegravir, and investigational agent, dolutegravir, are less prone to clinically significant drug interactions; whereas the investigational agent, elvitegravir, is more likely to exhibit interaction with other drugs because of coadministration with a pharmacokinetic enhancer (e.g., ritonavir, cobicistat). Important drug interactions exist between antiretrovirals and acid suppressants, antilipidemics, and medications for other chronic diseases. Therapeutic drug monitoring may represent a viable mechanism to identify and manage drug interactions in individual patients, but important barriers exist to widespread application in clinical practice.

\section{Conflict of Interest}

The authors declare no conflict of interest.

\section{References}

1. Palella, F.J., Jr.; Delaney, K.M.; Moorman, A.C.; Loveless, M.O.; Fuhrer, J.; Satten, G.A.; Aschman, D.J.; Holmberg, S.D. Declining morbidity and mortality among patients with advanced human immunodeficiency virus infection. HIV Outpatient Study Investigators. $N$. Engl. J. Med. 1998, 338, 853-860.

2. Zhang, L.; Huang, S.M.; Lesko, L.J. Transporter-mediated drug-drug interactions. Clin. Pharmacol. Ther. 2011, 89, 481-484. 
3. Pelkonen, O.; Turpeinen, M.; Hakkola, J.; Honkakoski, P.; Hukkanen, J.; Raunio, H. Inhibition and induction of human cytochrome P450 enzymes: current status. Arch. Toxicol. 2008, 82, $667-715$.

4. Zhou, S.; Yung Chan, S.; Cher Goh, B.; Chan, E.; Duan, W.; Huang, M.; McLeod, H.L. Mechanism-based inhibition of cytochrome P450 3A4 by therapeutic drugs. Clin. Pharmacokinet. 2005, 44, 279-304.

5. Tompkins, L.M.; Wallace, A.D. Mechanisms of cytochrome P450 induction. J. Biochem. Mol. Toxicol 2007, 21, 176-181.

6. Svard, J.; Spiers, J.P.; Mulcahy, F.; Hennessy, M. Nuclear Receptor-Mediated Induction of CYP450 by Antiretrovirals: Functional Consequences of NR1I2 (PXR) Polymorphisms and Differential Prevalence in Whites and Sub-Saharan Africans. J. Acquir. Immune Defic. Syndr. 2010, 55, 536-539.

7. Ingelman-Sundberg, M. Implications of polymorphic cytochrome p450-dependent drug metabolism for drug development. Drug Metab. Dispos. 2001, 29, 570-573.

8. Gatanaga, H.; Hayashida, T.; Tsuchiya, K.; Yoshino, M.; Kuwahara, T.; Tsukada, H.; Fujimoto, K.; Sato, I.; Ueda, M.; Horiba, M.; et al. Successful efavirenz dose reduction in HIV type 1infected individuals with cytochrome P450 2B6*6 and *26. Clin. Infect. Dis. 2007, 45, 1230-1237.

9. Bosma, P.J.; Chowdhury, J.R.; Bakker, C.; Gantla, S.; de Boer, A.; Oostra, B.A.; Lindhout, D.; Tytgat, G.N.; Jansen, P.L.; Oude Elferink, R.P.; et al. The genetic basis of the reduced expression of bilirubin UDP-glucuronosyltransferase 1 in Gilbert's syndrome. N. Engl. J. Med. 1995, 333, 1171-1175.

10. Hsu, A.; Granneman, G.R.; Witt, G.; Locke, C.; Denissen, J.; Molla, A.; Valdes, J.; Smith, J.; Erdman, K.; Lyons, N.; Niu, P.; Decourt, J.P.; Fourtillan, J.B.; Girault, J.; Leonard, J.M. Multiple-dose pharmacokinetics of ritonavir in human immunodeficiency virus-infected subjects. Antimicrob. Agents Chemother. 1997, 41, 898-905.

11. Kharasch, E.D.; Mitchell, D.; Coles, R.; Blanco, R. Rapid clinical induction of hepatic cytochrome P4502B6 activity by ritonavir. Antimicrob. Agents Chemother. 2008, 52, 1663-1669.

12. Abbott Laboratories. Norvir (ritonavir) tablets and oral solution prescribing information. Available online: http://www.rxabbott.com/pdf/norvirtab_pi.pdf (accessed on 14 July 2011).

13. Liedtke, M.D.; Rathbun, R.C. Drug interactions with antiretrovirals and warfarin. Expert Opin. Drug Saf. 2010, 9, 215-223.

14. Kashuba, A.D.; Tierney, C.; Downey, G.F.; Acosta, E.P.; Vergis, E.N.; Klingman, K.; Mellors, J.W.; Eshleman, S.H.; Scott, T.R.; Collier, A.C. Combining fosamprenavir with lopinavir/ritonavir substantially reduces amprenavir and lopinavir exposure: ACTG protocol A5143 results. AIDS 2005, 19, 145-152.

15. Corbett, A.H.; Patterson, K.B.; Tien, H.C.; Kalvass, L.A.; Eron, J.J.; Ngo, L.T.; Lim, M.L.; Kashuba, A.D. Dose separation does not overcome the pharmacokinetic interaction between fosamprenavir and lopinavir/ritonavir. Antimicrob. Agents Chemother. 2006, 50, 2756-2761.

16. Hill, A.; van der Lugt, J.; Sawyer, W.; Boffito, M. How much ritonavir is needed to boost protease inhibitors? Systematic review of 17 dose-ranging pharmacokinetic trials. AIDS 2009, 23, 2237-2245. 
17. Zeldin, R.K.; Petruschke, R.A. Pharmacological and therapeutic properties of ritonavir-boosted protease inhibitor therapy in HIV-infected patients. J. Antimicrob. Chemother. 2004, 53, 4-9.

18. Bristol-Myers Squibb. Reyataz (atazanavir sulfate) capsules prescribing information. Available online: http://us.gsk.com/products/assets/us_viracept.pdf (accesssed on 14 July 2011).

19. Sekar, V.; Spinosa-Guzman, S.; Meyvisch, P.; Stevens, T.; De Pauw, M.; Vangeneugden, T.; Hoetelmans, R. Cocktail study to investigate the in-vitro drug interaction potential of darunavir coadministered with low-dose ritonavir (DRV/r; RTV) on cytochrome P450 enzymes 2D6, 2C9 and 2C19. Presented at the 9th International Workshop on Clinical Pharmacology of HIV, New Orleans, LA, USA, 7-9 April 2008; Abstract P23.

20. Veronese, L.; Rautaureau, J.; Sadler, B.M.; Gillotin, C.; Petite, J.P.; Pillegand, B.; Delvaux, M.; Masliah, C.; Fosse, S.; Lou, Y.; Stein, D.S. Single-dose pharmacokinetics of amprenavir, a human immunodeficiency virus type 1 protease inhibitor, in subjects with normal or impaired hepatic function. Antimicrob. Agents Chemother. 2000, 44, 821-826.

21. Merck \& Co., Inc. Crixivan (indinavir sulfate) capsules prescribing information. Available online: http://www.merck.com/product/usa/pi_circulars/c/crixivan/crixivan_pi.pdf (accessed on 19 July 2011).

22. Yeh, R.F.; Gaver, V.E.; Patterson, K.B.; Rezk, N.L.; Baxter-Meheux, F.; Blake, M.J.; Eron, J.J., Jr.; Klein, C.E.; Rublein, J.C.; Kashuba, A.D. Lopinavir/ritonavir induces the hepatic activity of cytochrome P450 enzymes CYP2C9, CYP2C19, and CYP1A2 but inhibits the hepatic and intestinal activity of CYP3A as measured by a phenotyping drug cocktail in healthy volunteers. J. Acquir. Immune Defic. Syndr. 2006, 42, 52-60.

23. Dixit, V.; Hariparsad, N.; Li, F.; Desai, P.; Thummel, K.E.; Unadkat, J.D. Cytochrome P450 enzymes and transporters induced by anti-human immunodeficiency virus protease inhibitors in human hepatocytes: implications for predicting clinical drug interactions. Drug Metab. Dispos. 2007, 35, 1853-1859.

24. Agouron Pharmaceuticals, Inc. Viracept [package insert]. Available online: http://us.gsk.com/products/assets/us_viracept.pdf (accessed on 21 July 2011).

25. Eagling, V.A.; Back, D.J.; Barry, M.G. Differential inhibition of cytochrome P450 isoforms by the protease inhibitors, ritonavir, saquinavir and indinavir. Br. J. Clin. Pharmacol. 1997, 44, 190-194.

26. Dumond, J.B.; Vourvahis, M.; Rezk, N.L.; Patterson, K.B.; Tien, H.C.; White, N.; Jennings, S.H.; Choi, S.O.; Li, J.; Wagner, M.J.; et al. A phenotype-genotype approach to predicting CYP450 and P-glycoprotein drug interactions with the mixed inhibitor/inducer tipranavir/ritonavir. Clin. Pharmacol. Ther. 2010, 87, 735-742.

27. Voorman, R.L.; Payne, N.A.; Wienkers, L.C.; Hauer, M.J.; Sanders, P.E. Interaction of delavirdine with human liver microsomal cytochrome P450: inhibition of CYP2C9, CYP2C19, and CYP2D6. Drug Metab. Dispos. 2001, 29, 41-47.

28. Liu, P.; Foster, G.; LaBadie, R.R.; Gutierrez, M.J.; Sharma, A. Pharmacokinetic interaction between voriconazole and efavirenz at steady state in healthy male subjects. J. Clin. Pharmacol. 2008, 48, 73-84.

29. Scholler-Gyure, M.; Kakuda, T.N.; Van Solingen-Ristea, R.; Aharchi, F.; De Smedt, G.; Witek, J.; Nijs, S.; Vyncke, V.; Hoetelmans, R.M.W. Pharmacokinetic interaction between etravirine 
and fluconazole or voriconazole in HIV-negative volunteers. Presented at the 49th Interscience Conference on Antimicrobial Agents and Chemotherapy, San Francisco, CA, USA, 12-15 September, 2009; Abstract A1-1299.

30. Ma, Q.; Okusanya, O.O.; Smith, P.F.; Dicenzo, R.; Slish, J.C.; Catanzaro, L.M.; Forrest, A.; Morse, G.D. Pharmacokinetic drug interactions with non-nucleoside reverse transcriptase inhibitors. Expert Opin. Drug Metab. Toxicol. 2005, 1, 473-485.

31. Back, D.; Gibbons, S.; Khoo, S. Pharmacokinetic drug interactions with nevirapine. J. Acquir. Immune Defic. Syndr. 2003, 34, S8-S14.

32. Crauwels, H.M.; van Heeswijk, R.P.G.; Stevens, T.; Stevens, M.; Buelens, A.; Boven, K.; Hoetelmans, R.M.W. The effect of TMC278, a next-generation non-nucleoside reverse transcriptase inhibitor (NNRTI) on CYP3A activity in vivo. Presented at the 10th International Workshop on Clinical Pharmacology of HIV Therapy, Amsterdam, The Netherlands, 15-17 April 2009; Abstract P28.

33. Merck Sharp \& Dohme Corp. Isentress (raltegravir) tablets prescribing information. Available online: http://www.merck.com/product/usa/pi_circulars/i/isentress/isentress_pi.pdf (accessed on 21 July 2011).

34. German, P.; Wang, M.; Warren, D.; Kearney, B.P. Pharmacokinetic interaction between norgestimate/ethinyl estradiol and elvitegravir/cobicistat/emtricitabine/tenofovir single tablet regimen. Presented at the 12th International Workshop on Clinical Pharmacology of HIV Therapy, Miami, FL, USA, 13-15 April 2011; Abstract O_17.

35. Min, S.; Song, I.; Borland, J.; Chen, S.; Lou, Y.; Fujiwara, T.; Piscitelli, S.C. Pharmacokinetics and safety of S/GSK1349572, a next-generation HIV integrase inhibitor, in healthy volunteers. Antimicrob. Agents Chemother. 2010, 54, 254-258.

36. Hyland, R.; Dickins, M.; Collins, C.; Jones, H.; Jones, B. Maraviroc: in vitro assessment of drugdrug interaction potential. Br. J. Clin. Pharmacol. 2008, 66, 498-507.

37. Sekar, V.; Guzman, S.; Stevens, T.; Depaepe, E.; Lefebvre, E.; Hoetelmans, R. Absolute bioavailability of TMC114, administered in the absence and presence of low-dose ritonavir. Presented at the 7th International Workshop on Clinical Pharmacology of HIV Therapy, Lisbon, Portugal, 20-22 April 2006; Abstract P86.

38. Sekar, V.; Spinosa-Guzman, S.; Lefebvre, E.; Hoetelmans, R. Clinical pharmacology of TMC114 a new HIV protease inhibitor. Presented at the 16th International AIDS Conference, Toronto, Canada, 13-18 August 2006; Abstract TUPE0083.

39. Sekar, V.; Kestens, D.; Spinosa-Guzman, S.; De Pauw, M.; De Paepe, E.; Vangeneugden, T.; Lefebvre, E.; Hoetelmans, R.M. The effect of different meal types on the pharmacokinetics of darunavir (TMC114)/ritonavir in HIV-negative healthy volunteers. J. Clin. Pharmacol. 2007, 47, 479-484.

40. Sekar, V.J.; De Pauw, M.; Marien, K.; Peeters, M.; Lefebvre, E.; Hoetelmans, R.M. Pharmacokinetic interaction between TMC114/r and efavirenz in healthy volunteers. Antivir. Ther. 2007, 12, 509-514.

41. Sekar, V.; Lefebvre, E.; Marien, K.; De Pauw, M.; Vangeneugden, T.; Pozniak, A.; Hoetelmans, R.M. Pharmacokinetic interaction between nevirapine and darunavir with low-dose ritonavir in HIV-1-infected patients. Br. J. Clin. Pharmacol. 2009, 68, 116-119. 
42. Scholler-Gyure, M.; Kakuda, T.N.; Sekar, V.; Woodfall, B.; De Smedt, G.; Lefebvre, E.; Peeters, M.; Hoetelmans, R.M. Pharmacokinetics of darunavir/ritonavir and TMC125 alone and coadministered in HIV-negative volunteers. Antivir. Ther. 2007, 12, 789-796.

43. Sekar, V.; Lefebvre, E.; Spinosa-Guzman, S.; Boogaerts, G.; Kestens, D.; De Pauw, M.; De Paepe, E.; Workman, C.; Hoetelmans, R. Pharmacokinetic interaction between the protease inhibitors TMC114 and lopinavir/ritonavir. Presented at the 46th Interscience Conference on Antimicrobial Agents and Chemotherapy, San Francisco, CA, USA, 27-30 September 2006; Abstract A-367.

44. Sekar, V.J.; Lefebvre, E.; Marien, K.; De Pauw, M.; Vangeneugden, T.; Hoetelmans, R.M. Pharmacokinetic interaction between darunavir and saquinavir in HIV-negative volunteers. Ther. Drug Monit. 2007, 29, 795-801.

45. Sekar, V.J.; Lefebvre, E.; De Marez, T.; Spinosa-Guzman, S.; De Pauw, M.; De Paepe, E.; Vangeneugden, T.; Hoetelmans, R.M. Pharmacokinetics of darunavir (TMC114) and atazanavir during coadministration in HIV-negative, healthy volunteers. Drugs R. D. 2007, 8, 241-248.

46. Sekar, V.; Lefebvre, E.; De Marez, T.; De Pauw, M.; De Paepe, E.; Vangeneugden, T.; Hoetelmans, R.M. Pharmacokinetic interaction between indinavir and darunavir with low-dose ritonavir in healthy volunteers. Intervirology 2010, 53, 176-182.

47. Bristol-Myers Squibb. Sustiva (efavirenz) capsules and tablets prescribing information. Available online: http://packageinserts.bms.com/pi/pi_sustiva.pdf (accessed on 21 July 2011).

48. Scholler-Gyure, M.; Boffito, M.; Pozniak, A.L.; Leemans, R.; Kakuda, T.N.; Woodfall, B.; Vyncke, V.; Peeters, M.; Vandermeulen, K.; Hoetelmans, R.M. Effects of different meal compositions and fasted state on the oral bioavailability of etravirine. Pharmacotherapy 2008, $28,1215-1222$.

49. Crauwels, H.; van Heeswijk, R.P.; Bollen, A.; Stevens, M.; Buelens, A.; Boven, K.; Hoetelmans, R.M.W. The effect of different types of food on the bioavailability of TMC278, an investigational non-nucleoside reverse transcriptase inhibitor (NNRTI). Presented at the 9th International Workshop on Clinical Pharmacology of HIV Therapy, New Orleans, LA, USA, 7-9 April 2008; Abstract P32.

50. von Moltke, L.L.; Greenblatt, D.J.; Granda, B.W.; Giancarlo, G.M.; Duan, S.X.; Daily, J.P.; Harmatz, J.S.; Shader, R.I. Inhibition of human cytochrome P450 isoforms by nonnucleoside reverse transcriptase inhibitors. J. Clin. Pharmacol. 2001, 41, 85-91.

51. European Medicines Agency. CHMP Assessment Report for Intelence. 2008. Available online: $\mathrm{http} / /$ www.emea.europa.eu/humandocs/PDFs/EPAR/intelence/H-900-en6.pdf (accessed on 1 March 2010).

52. Hughes, C.A.; Robinson, L.; Tseng, A.; MacArthur, R.D. New antiretroviral drugs: a review of the efficacy, safety, pharmacokinetics, and resistance profile of tipranavir, darunavir, etravirine, rilpivirine, maraviroc, and raltegravir. Expert Opin. Pharmacother. 2009, 10, 2445-2466.

53. Scholler-Gyure, M.; Kakuda, T.N.; Raoof, A.; De Smedt, G.; Hoetelmans, R.M. Clinical pharmacokinetics and pharmacodynamics of etravirine. Clin. Pharmacokinet. 2009, 48, 561-574.

54. Scholler-Gyure, M.; Woodfall, B.; De Marez, T.; De Smedt, G.; Peeters, M.; Vandermeulen, K.; Hoetelmans, R. Pharmacokinetics of TMC125 with atazanavir and atazanavir/ritonavir. 
Presented at the 8th International Congress on Drug Therapy in HIV Infection, Glasgow, UK, 12-16 November 2006; Abstract P278.

55. Scholler-Gyure, M.; Woodfall, B.; Bollen, A.; Peeters, M.; Vandermeulen, K.; Hoetelmans, R. Pharmacokinetics (pk) of amprenavir (APV) and TMC125 in HIV-infected volunteers receiving TMC125 with fosamprenavir/ritonavir (fosAPV/RTV). Presented at the 46th Interscience Conference on Antimicrobial Agents and Chemotherapy, San Francisco, CA, USA, 27-30 September 2006; Abstract A-370.

56. Mills, A.; Cahn, P.; Molina, J.M.; Nijs, S.; Vingerhoets, J.; Witek, J. Etravirine demonstrates durable efficacy in treatment-experienced patients in the DUET trials: pooled 96-week results. Presented at the 5th International AIDS Society Conference on HIV Pathogenesis, Treatment and Prevention, Capetown, South Africa, 19-22 July 2009; Abstract MOPEB036.

57. Baede, P.; Piscitelli, S.; Graham, N.; Van't Klooster, G. Drug interactions with TMC125, a potent next generation NNRTI. Presented at the 42nd Interscience Conference on Antimicrobial Agents and Chemotherapy, San Diego, CA, USA, 27-30 September 2002; Abstract A-1827.

58. Scholler-Gyure, M.; Kraft, M.; Hoetelmans, R.; Vyncke, V.; Vandermeulen, K.; Peeters, M.; Bastiaanse, L.; Debroye, C.; Woodfall, B.; Baeten, B. Significant decrease in TMC125 exposures when co-administered with tipranavir boosted with ritonavir in healthy subjects. Presented at the 13th Conference on Retroviruses and Opportunistic Infections, Denver, CO, USA, 5-8 February 2006; Abstract 583.

59. Hoetelmans, R.; van Heeswijk, R.; Kestens, D.; Stevens, M.; Peeters, M.; Williams, P.; Bastlaanse, L.; Buffels, R.; Woodfall, B. Pharmacokinetic interaction between the novel nonnucleoside reverse transcriptase inhibitor (NNRTI) TMC278 and tenofovir disoproxil fumarate (TDF) in healthy volunteers. Presented at the 3rd International AIDS Society Conference on HIV Pathogenesis and Treatment, Rio de Janeiro, Brazil, 24-27 July 2005; Abstract WePe3.3C15.

60. van Heeswijk, R.P.G.; Hoetelmans, R.M.W.; Kestens, D.; Stevens, M.; Peeters, M.; Williams, P.; Woodfall, B.; Boven, K. The pharmacokinetic (PK) interaction between TMC278, a next generation non-nucleoside reverse transcriptase inhibitor (NNRTI), and once daily darunavir/ritonavir (DRV/r) in HIV-negative volunteers. Presented at the 42nd Interscience Conference on Antimicrobial Agents and Chemotherapy, Chicago, IL, USA, 17-20 September 2007; Abstract H-1042.

61. Hoetelmans, R.; van Heeswijk, R.; Kestens, D.; et al. Pharmacokinetic interaction between TMC278, and investigational NNRTI and lopinavir/r in healthy volunteers. Presented at the 10th European AIDS Conference, Dublin, Ireland, 17-20 November 2005; abstract PE4.3/1.

62. Tibotec Therapeutics. Edurant (rilpivirine) tablets prescribing information. Available online: http://www.edurant-info.com/sites/default/files/EDURANT-PI.pdf (accessed on 21 July 2011).

63. Pfizer, Inc. Maraviroc tablets NDA 22-128: Antiviral Drugs Advisory Committee briefing document. Available online: http://www.fda.gov/OHRMS/DOCKTES/AC/07/briefing/20074283b-01-Pfizer.pdf (accessed on 9 July 2011).

64. ViiV Healthcare. Selzentry (maraviroc) tablets prescribing information. Available online: http:/www.viivhealthcare.com/products/ /media/Files/G/GlaxoSmithKline-Plc/Attachments/ pdfs/products/us_selzentry_jul2011.pdf(accessed on 21 July 2011). 
65. Abel, S.; Jenkins, T.M.; Whitlock, L.A.; Ridgway, C.E.; Muirhead, G.J. Effects of CYP3A4 inducers with and without CYP3A4 inhibitors on the pharmacokinetics of maraviroc in healthy volunteers. Br. J. Clin. Pharmacol. 2008, 65, 38-46.

66. Pozniak, A.L.; Boffito, M.; Russell, D.; Ridgway, C.E.; Muirhead, G.J. A novel probe drug interaction study to investigate the effect of selected antiretroviral combinations on the pharmacokinetics of a single oral dose of maraviroc in HIV-positive subjects. Br. J. Clin. Pharmacol. 2008, 65, 54-59.

67. Kakuda, T.N.; Abel, S.; Davis, J.; Hamlin, J.; Scholler-Gyure, M.; Mack, R.; Ndongo, N.; Petit, W.; Ridgway, C.; Sekar, V.; Tweedy, S.; Hoetelmans, R.M. Pharmacokinetic interactions of maraviroc with darunavir-ritonavir, etravirine, and etravirine-darunavir-ritonavir in healthy volunteers: results of two drug interaction trials. Antimicrob. Agents Chemother. 2011, 55, 2290-2296.

68. Abel, S.; Russell, D.; Taylor-Worth, R.J.; Ridgway, C.E.; Muirhead, G.J. Effects of CYP3A4 inhibitors on the pharmacokinetics of maraviroc in healthy volunteers. Br. J. Clin. Pharmacol. 2008, 65, 27-37.

69. Ramanathan, S.; Abel, S.; Tweedy, S.; West, S.; Hui, J.; Kearney, B.P. Pharmacokinetic interaction of ritonavir-boosted elvitegravir and maraviroc. J. Acquir. Immune Defic. Syndr. 2010, 53, 209-214.

70. Andrews, E.; Glue, P.; Fang, J.; Crownover, P.; Tressler, R.; Damle, B. Assessment of the pharmacokinetics of co-administered maraviroc and raltegravir. Br. J. Clin. Pharmacol. 2010, 69, 51-57.

71. Kobayashi, M.; Yoshinaga, T.; Seki, T.; Wakasa-Morimoto, C.; Brown, K.W.; Ferris, R.; Foster, S.A.; Hazen, R.J.; Miki, S.; Suyama-Kagitani, A.; et al. In Vitro antiretroviral properties of S/GSK1349572, a next-generation HIV integrase inhibitor. Antimicrob. Agents Chemother. 2011, $55,813-821$.

72. Kassahun, K.; McIntosh, I.; Cui, D.; Hreniuk, D.; Merschman, S.; Lasseter, K.; Azrolan, N.; Iwamoto, M.; Wagner, J.A.; Wenning, L.A. Metabolism and disposition in humans of raltegravir (MK-0518), an anti-AIDS drug targeting the human immunodeficiency virus 1 integrase enzyme. Drug Metab. Dispos. 2007, 35, 1657-1663.

73. Zhang, D.; Chando, T.J.; Everett, D.W.; Patten, C.J.; Dehal, S.S.; Humphreys, W.G. In vitro inhibition of UDP glucuronosyltransferases by atazanavir and other HIV protease inhibitors and the relationship of this property to in vivo bilirubin glucuronidation. Drug Metab. Dispos. 2005, 33, 1729-1739.

74. Iwamoto, M.; Wenning, L.A.; Mistry, G.C.; Petry, A.S.; Liou, S.Y.; Ghosh, K.; Breidinger, S.; Azrolan, N.; Gutierrez, M.J.; Bridson, W.E.; et al. Atazanavir modestly increases plasma levels of raltegravir in healthy subjects. Clin. Infect. Dis. 2008, 47, 137-140.

75. Cattaneo, D.; Ripamonti, D.; Baldelli, S.; Cozzi, V.; Conti, F.; Clementi, E. Exposure-related effects of atazanavir on the pharmacokinetics of raltegravir in HIV-1-infected patients. Ther. Drug Monit. 2010, 32, 782-786.

76. Hanley, W.D.; Wenning, L.A.; Moreau, A.; Kost, J.T.; Mangin, E.; Shamp, T.; Stone, J.A.; Gottesdiener, K.M.; Wagner, J.A.; Iwamoto, M. Effect of tipranavir-ritonavir on pharmacokinetics of raltegravir. Antimicrob. Agents Chemother. 2009, 53, 2752-2755. 
77. Cooper, D.A.; Steigbigel, R.T.; Gatell, J.M.; Rockstroh, J.K.; Katlama, C.; Yeni, P.; Lazzarin, A.; Clotet, B.; Kumar, P.N.; Eron, J.E.; et al. Subgroup and resistance analyses of raltegravir for resistant HIV-1 infection. N. Engl. J. Med. 2008, 359, 355-365.

78. Anderson, M.S.; Kakuda, T.N.; Hanley, W.; Miller, J.; Kost, J.T.; Stoltz, R.; Wenning, L.A.; Stone, J.A.; Hoetelmans, R.M.; Wagner, J.A.; Iwamoto, M. Minimal pharmacokinetic interaction between the human immunodeficiency virus nonnucleoside reverse transcriptase inhibitor etravirine and the integrase inhibitor raltegravir in healthy subjects. Antimicrob. Agents Chemother. 2008, 52, 4228-4232.

79. Menard, A.; Solas, C.; Mokthari, S.; Bregigeon, S.; Drogoul, M.P.; Tamalet, C.; Lacarelle, B.; Martin, I.P. Etravirine-raltegravir, a marked interaction in HIV-1-infected patients: about four cases. AIDS 2009, 23, 869-871.

80. Barrail-Tran, A.; Yazdanpanah, Y.; Fagard, C.; Colin, C.; Piketty, C.; Descamps, D.; Molina, J.M.; Chene, G.; Taburet, A.M. Lack of Interaction between Etravirine and Raltegravir plus Darunavir/Ritonavir When Combined in Treatment-experienced Patients: A Substudy of the ANRS 139 TRIO Trial. Presented at the 17th Conference on Retroviruses and Opportunistic Infections, San Francisco, CA, USA, 16-19 February 2010; Abstract 606.

81. Wenning, L.; Anderson, M.; Petry, A.; Friedman, E.; Kost, J.; James, S.; Strohmaier, K.M.; Miller, D.; Merschman, S.; Bieberdorf, F.; et al. Raltegravir (RAL) dose proportionality and effect of food. Presented at the 47th Interscience Conference on Antimicrobial Agents and Chemotherapy, San Francisco, CA, USA, 17-20 September 2007; Abstract H-1046.

82. Ramanathan, S.; Mathias, A.A.; German, P.; Kearney, B.P. Clinical pharmacokinetic and pharmacodynamic profile of the HIV integrase inhibitor elvitegravir. Clin. Pharmacokinet. 2011, 50, 229-244.

83. Kawaguchi, I.; Ishikawa, T.; Ishibashi, M.; Irie, S.; Kakee, A. Safety and pharmacokinetics of single oral dose of JTK-303/GS-9137, a novel HIV integrase inhibitor, in healthy volunteers. Presented at the 13th Conference on Retroviruses and Opportunistic Infections, Denver, CO, USA, 5-9 February 2006; Abstract 580.

84. Ramanathan, S.; Shen, G.; Hinkle, J.; Enejosa, J.; Kearney, B.P. Pharmacokinetics of coadministered ritonavir-boosted elvitegravir and zidovudine, didanosine, stavudine, or abacavir. J. Acquir. Immune Defic. Syndr. 2007, 46, 160-166.

85. Ramanathan, S.; Shen, G.; Cheng, A.; Kearney, B.P. Pharmacokinetics of emtricitabine, tenofovir, and GS-9137 following coadministration of emtricitabine/tenofovir disoproxil fumarate and ritonavir-boosted GS-9137. J. Acquir. Immune Defic. Syndr. 2007, 45, 274-279.

86. Mathias, A.A.; Hinkle, J.; Shen, G.; Enejosa, J.; Piliero, P.J.; Sekar, V.; Mack, R.; Tomaka, F.; Kearney, B.P. Effect of ritonavir-boosted tipranavir or darunavir on the steady-state pharmacokinetics of elvitegravir. J. Acquir. Immune Defic. Syndr. 2008, 49, 156-162.

87. Ramanathan, S.; Kakuda, T.N.; Mack, R.; West, S.; Kearney, B.P. Pharmacokinetics of elvitegravir and etravirine following coadministration of ritonavir-boosted elvitegravir and etravirine. Antivir. Ther. 2008, 13, 1011-1017.

88. Ramanathan, S.; Mathias, A.A.; Shen, G.; Holmes, C.; Kearney, B.P. Lack of clinically relevant drug-drug interaction between ritonavir-boosted GS-9137 (elvitegravir) and fosamprenavir/r. 
Presented at the 4th IAS Conference on HIV Pathogenesis, Treatment and Prevention, Sydney, Australia, 22-25 July 2007; Abstract WEPEB014.

89. Mathias, A.; West, S.; Enejosa, J.; Kearney, B. A pharmacokinetic interaction between lopinavir/r and elvitegravir. Presented at the 47th Annual Interscience Conference on Antimicrobial Agents and Chemotherapy, Chicago, IL, USA, 17-20 September 2007; Abstract A-1418.

90. Mathias, A.; Ramanathan, S.; Hinkle, J.; West, S.; Enejosa, J.; Kearney, B. Effect of atazanavir/r on the steady-state pharmacokinetics of elvitegravir. Presented at the 47th Interscience Conference on Antimicrobial Agents and Chemotherapy, Chicago, IL, USA, 17-20 September 2007; Abstract A-1417.

91. Ramanathan, S.; West, S.; Hui, J.; Chuck, S.L.; Kearney, B.P. Clinical pharmacokinetics of oncedaily elvitegravir boosted by atazanavir versus ritonavir. Presented at the 9th International Workshop on Clinical Pharmacology of HIV Therapy, New Orleans, LA, USA, 7-9 April 2008; Abstract O18.

92. Song, I.; Min, S.S.; Borland, J.; Lou, Y.; Chen, S.; Patel, P.; Ishibashi, T.; Piscitelli, S.C. The effect of lopinavir/ritonavir and darunavir/ritonavir on the HIV integrase inhibitor S/GSK1349572 in healthy participants. J. Clin. Pharmacol. 2011, 51, 237-242.

93. Song, I.; Borland, J.; Chen, S., Patel, P.; Wajima, T.; Peppercorn, A.; Piscitelli, S. Effect of food on the pharmacokinetics of the integrase inhibitor, dolutegravir (S/GSK1349572). Presented at the 12th International Workshop on Clinical Pharmacology of HIV Therapy, Miami, FL, USA, 13-15 May 2011; Abstract P_12.

94. Song, I.; Borland, J.; Lou, Y.; Chen, S.; Patel, P.; Guta, P.; Wajima, T.; Peppercorn, A.; Piscitelli, S. Effects of enzyme inducers, tipranavir and efavirenz, on the pharmacokinetics of the integrase inhibitor, dolutegravir (S/GSK1349572). Presented at the 12th International Workshop on Clinical Pharmacology of HIV Therapy, Miami, FL, USA, 13-15 May 2011; Abstract O_02.

95. Song, I.; Borland, J.; Chen, S.; Lou, Y.; Peppercorn, A.; Wajima, T.; Min, S.; Piscitelli, S.C. Effect of atazanavir and atazanavir/ritonavir on the pharmacokinetics of the next-generation HIV integrase inhibitor, S/GSK1349572. Br. J. Clin. Pharmacol. 2011, 72, 103-108.

96. Song, I.; Borland, J.; Min, S.; Lou, Y.; Chen, S.; Patel, P.; Wajima, T.; Piscitelli, S.C. Effects of etravirine alone and with ritonavir-boosted protease inhibitors on the pharmacokinetics of dolutegravir. Antimicrob. Agents Chemother. 2011, 55, 3517-3521.

97. Song, I.; Min, S.S.; Borland, J.; Lou, Y.; Chen, S.; Ishibashi, T.; Wajima, T.; Piscitelli, S.C. Lack of interaction between the HIV integrase inhibitor S/GSK1349572 and tenofovir in healthy subjects. J. Acquir. Immune Defic. Syndr. 2010, 55, 365-367.

98. Hazuda, D.J.; Felock, P.; Witmer, M.; Wolfe, A.; Stillmock, K.; Grobler, J.A.; Espeseth, A.; Gabryelski, L.; Schleif, W.; Blau, C.; Miller, M.D. Inhibitors of strand transfer that prevent integration and inhibit HIV-1 replication in cells. Science 2000, 287, 646-650.

99. Kiser, J.J.; Bumpass, J.B.; Meditz, A.L.; Anderson, P.L.; Bushman, L.; Ray, M.; Predhomme, J.A.; Rower, J.; Mawhinney, S.; Brundage, R. Effect of antacids on the pharmacokinetics of raltegravir in human immunodeficiency virus-seronegative volunteers. Antimicrob. Agents Chemother. 2010, 54, 4999-5003. 
100. Ramanathan, S.; Shen, G.; Hinkle, J.; Enejosa, J.; Kearney, B. Pharmacokinetic evaluation of drug interactions with ritonavir-boosted HIV integrase inhibitor GS-9137 (elvitegravir) and acidreducing agents. Presented at the 8th International Workshop on Clinical Pharmacology of HIV Therapy, Budapest, Hungary, 16-18 April 2007; Abstract 69.

101. Patel, P.; Song, I.; Borland, J.; Patel, A.; Lou, Y.; Chen, S.; Wajima, T.; Peppercorn, A.; Min, S.S.; Piscitelli, S.C. Pharmacokinetics of the HIV integrase inhibitor S/GSK1349572 coadministered with acid-reducing agents and multivitamins in healthy volunteers. J. Antimicrob. Chemother. 2011, 66, 1567-1572.

102. van Heeswijk, R.; Sabo, J.P.; Copper, C., Cameron, W.; MacGregor, T.R.; Elgadi, M.; Harris, F.; McCallister, S.; Mayers, D. The pharmacokinetic interactions between tipranavir/ritonavir $500 \mathrm{mg} / 200 \mathrm{mg}$ bid (TPV/r) and atorvastatin, antacid and CYP3A4 in healthy volunteers. Presented at the 5th International workshop on Clinical Pharmacology in HIV Therapy, Rome, Italy, 1-3 April 2004; Abstract 5.2.

103. Kiser, J.J.; Lichtenstein, K.A.; Anderson, P.L.; Fletcher, C.V. Effects of esomeprazole on the pharmacokinetics of atazanavir and fosamprenavir in a patient with human immunodeficiency virus infection. Pharmacotherapy 2006, 26, 511-514.

104. Ford, S.L.; Wire, M.B.; Lou, Y.; Baker, K.L.; Stein, D.S. Effect of antacids and ranitidine on the single-dose pharmacokinetics of fosamprenavir. Antimicrob. Agents Chemother. 2005, 49, 467-469.

105. Lin, J.H.; Chen, I.W.; Vastag, K.J.; Ostovic, D. pH-dependent oral absorption of L-735,524, a potent HIV protease inhibitor, in rats and dogs. Drug Metab. Dispos. 1995, 23, 730-735.

106. van Heeswijk, R.P.; Hoetelmans, R.M.; Kestens, D.; Stevens, M.; Peeters, M.; Williams, P.; Woodfall, B.; Boven, K. The pharmacokinetic (PK) interaction between famotidine and TMC278, a next generation non-nucleoside reverse transcriptase inhibitor (NNRTI), in HIVnegative volunteers. Presented at the 4th International AIDS Society Conference on HIV Pathogenesis, Treatment, and Prevention, Sydney, Australia, 22-25 July 2007; Abstract TUPDB01.

107. Crauwels, H.M.; van Heeswijk, R.P.G.; Kestens, D.; Stevens, M.; Buelens, A.; Boven, K.; Hoetelmans, R.M.W. The pharmacokinetic (PK) interaction between omeprazole and TMC278, an investigational non-nucleoside reverse transcriptase inhibitor (NNRTI). Presented at the 9th International Congress on Drug Therapy in HIV Infection, Glasgow, UK, 9-13 November 2008; Abstract P239.

108. Shelton, M.J.; Ford, S.L.; Borland, J.; Lou, Y.; Wire, M.B.; Min, S.S.; Xue, Z.G.; Yuen, G. Coadministration of esomeprazole with fosamprenavir has no impact on steady-state plasma amprenavir pharmacokinetics. J. Acquir. Immune Defic. Syndr. 2006, 42, 61-67.

109. Panel on Antiretroviral Guidelines for Adults and Adolescents. Guidelines for the use of antiretroviral agents in HIV-1-infected adults and adolescents. Department of Health and Human Services. Available online: http://www.aidsinfo.nih.gov/ContentFiles/AdultandAdolescentGL.pdf (accessed on 1 July 2011)

110. Tappouni, H.L.; Rublein, J.C.; Donovan, B.J.; Hollowell, S.B.; Tien, H.C.; Min, S.S.; Theodore, D.; Rezk, N.L.; Smith, P.C.; Tallman, M.N.; Raasch, R.H.; Kashuba, A.D. Effect of omeprazole 
on the plasma concentrations of indinavir when administered alone and in combination with ritonavir. Am. J. Health Syst. Pharm. 2008, 65, 422-428.

111. Iwamoto, M.; Wenning, L.A.; Nguyen, B.Y.; Teppler, H.; Moreau, A.R.; Rhodes, R.R.; Hanley, W.D.; Jin, B.; Harvey, C.M.; Breidinger, S.A.; Azrolan, N.; Farmer, H.F., Jr.; Isaacs, R.D.; Chodakewitz, J.A.; Stone, J.A.; Wagner, J.A. Effects of omeprazole on plasma levels of raltegravir. Clin. Infect. Dis. 2009, 48, 489-492.

112. Rhame, F.; Matson, M.; Wood, D.; Comisar, W.; Petry, A.; Liu, C.; Wenning, L.; Wagner, J.; Iwamoto, M.; Brainard, D. Effects of famotidine and omeprazole on raltegravir pharmacokinetics in HIV-infected individuals. Presented at the 12th European AIDS Conference, Cologne, Germany, 11-14 November 2009; Abstract PE4.1/1.

113. Boehringer Ingelheim Pharmaceuticals, Inc. Aptivus (tipranavir) capsules prescribing information. Available online: http://bidocs.boehringer-ingelheim.com/BIWebAccess/ ViewServlet.ser?docBase=renetnt\&folderPath=/Prescribing + Information/PIs/Aptivus/10003515 +US+01.pdf (accessed on 28 July 2011).

114. Saberi, P.; Ranatunga, D.K.; Quesenberry, C.P.; Silverberg, M.J. Clinical implications of the nelfinavir-proton pump inhibitor drug interaction in patients with human immunodeficiency virus. Pharmacotherapy 2011, 31, 253-261.

115. Fang, A.F.; Damle, B.D.; LaBadie, R.R.; Crownover, P.H.; Hewlett, D., Jr.; Glue, P.W. Significant decrease in nelfinavir systemic exposure after omeprazole coadministration in healthy subjects. Pharmacotherapy 2008, 28, 42-50.

116. Sekar, V.J.; Lefebvre, E.; De Pauw, M.; Vangeneugden, T.; Hoetelmans, R.M. Pharmacokinetics of darunavir/ritonavir and ketoconazole following co-administration in HIV-healthy volunteers. Br. J. Clin. Pharmacol. 2008, 66, 215-221.

117. Abbott Laboratories. Kaletra (lopinavir/ritonavir) tablets and oral solution prescribing information. Available online: http://www.rxabbott.com/pdf/kaletratabpi.pdf (accessed on 28 July 2011).

118. Bertz, R.; Wong, C.; Carothers, L.; Lauva, I.; Dennis, S.; Valdes, J. Evaluation of the pharmacokinetics of multiple dose ritonavir and ketoconazole in combination. Clin. Pharmacol. Ther. 1998, 63, 230.

119. Viiv Healthcare. Lexiva (fosamprenavir calcium) tablets and oral suspension prescribing information. Available online: http://us.gsk.com/products/assets/us_lexiva.pdf (accessed on 8 September 2011).

120. Crommentuyn, K.M.; Mulder, J.W.; Sparidans, R.W.; Huitema, A.D.; Schellens, J.H.; Beijnen, J.H. Drug-drug interaction between itraconazole and the antiretroviral drug lopinavir/ritonavir in an HIV-1-infected patient with disseminated histoplasmosis. Clin. Infect. Dis. 2004, 38, e73-e75.

121. Pfizer-Roerig. Vfend (voriconazole) tablets, oral suspension, and IV prescribing information. Available online: http://labeling.pfizer.com/ShowLabeling.aspx?id=618 (accessed on 8 September 2011).

122. Damle, B.; LaBadie, R.; Crownover, P.; Glue, P. Pharmacokinetic interactions of efavirenz and voriconazole in healthy volunteers. Br. J. Clin. Pharmacol. 2008, 65, 523-530.

123. Kaul, S.; Ji, P.; Dudley, J.; Wu, W.; Whigan, D.; Olszyk, C.; Nandy, P.; Hughes, E.; Grasela, D. Pharmacokinetic interaction between efavirenz and diltiazem or itraconazole after multiple-dose 
administration in adult healthy subjects. Presented at the 14th Conference on Retroviruses and Opportunistic Infections, Los Angeles, CA, USA, 25-28 February 2007; Abstract 561.

124. Koo, H.L.; Hamill, R.J.; Andrade, R.A. Drug-drug interaction between itraconazole and efavirenz in a patient with AIDS and disseminated histoplasmosis. Clin. Infect. Dis. 2007, 45, e77-e79.

125. Huet, E.; Hadji, C.; Hulin, A.; Botterel, F.; Bretagne, S.; Levy, Y. Therapeutic monitoring is necessary for the association itraconazole and efavirenz in a patient with AIDS and disseminated histoplasmosis. AIDS 2008, 22, 1885-1886.

126. Sriwiriyajan, S.; Mahatthanatrakul, W.; Ridtitid, W.; Jaruratanasirikul, S. Effect of efavirenz on the pharmacokinetics of ketoconazole in HIV-infected patients. Eur. J. Clin. Pharmacol. 2007, 63, 479-483.

127. Krishna, G.; Moton, A.; Ma, L.; Martinho, M.; Seiberling, M.; McLeod, J. Effects of oral posaconazole on the pharmacokinetics of atazanavir alone and with ritonavir or with efavirenz in healthy adult volunteers. J. Acquir. Immune. Defic. Syndr. 2009, 51, 437-444.

128. la Porte, C.J.; Sabo, J.P.; Elgadi, M.; Cameron, D.W. Interaction studies of tipranavir-ritonavir with clarithromycin, fluconazole, and rifabutin in healthy volunteers. Antimicrob. Agents Chemother. 2009, 53, 162-173.

129. Agarwala, S.; Gray, K.; Nettle, R.; et al. Lack of pharmacokinetic interaction between atazanavir, ritonavir and fluconazole dosed to steady state in healthy volunteers. Presented at the 46th Interscience Conference on Antimicrobial Agents and Chemotherapy, San Francisco, CA, USA, 27-30 September 2006; Abstract A-382.

130. Geel, J.; Pitt, J.; Orrell, C.; van Dyk, M.; Wood, R. Effect of fluconazole on nevirapine pharmacokinetics. Presented at the 11th International AIDS Conference, Bangkok, Thailand, 11-16 July 2004; Abstract TuPeB4606.

131. Stone, J.A.; Li, S.; Winchell, G.; Bi, S.; Wickersham, P.; Schwartz, M.; Kartsonis, N.; Sable, C. Population Pharmacokinetics of Caspofungin in Candidiasis Patients. Presented at the 43rd Interscience Conference on Antimicrobial Agents and Chemotherapy, Chicago, IL, USA, 14-17 September 2003; Abstract A-1571.

132. Dube, M.P.; Stein, J.H.; Aberg, J.A.; Fichtenbaum, C.J.; Gerber, J.G.; Tashima, K.T.; Henry, W.K.; Currier, J.S.; Sprecher, D.; Glesby, M.J. Guidelines for the evaluation and management of dyslipidemia in human immunodeficiency virus (HIV)-infected adults receiving antiretroviral therapy: recommendations of the HIV Medical Association of the Infectious Disease Society of America and the Adult AIDS Clinical Trials Group. Clin. Infect. Dis. 2003, 37, 613-627.

133. Fichtenbaum, C.J.; Gerber, J.G.; Rosenkranz, S.L.; Segal, Y.; Aberg, J.A.; Blaschke, T.; Alston, B.; Fang, F.; Kosel, B.; Aweeka, F. Pharmacokinetic interactions between protease inhibitors and statins in HIV seronegative volunteers: ACTG Study A5047. AIDS 2002, 16, 569-577.

134. Busti, A.J.; Bain, A.M.; Hall, R.G., 2nd; Bedimo, R.G.; Leff, R.D.; Meek, C.; Mehvar, R. Effects of atazanavir/ritonavir or fosamprenavir/ritonavir on the pharmacokinetics of rosuvastatin. $J$. Cardiovasc. Pharmacol. 2008, 51, 605-610.

135. Carr, R.A.; Andre, R.J.; Bertz, R.J.; Hsu, A.; Lam, W.; Chang, M.; Chen, P.; Williams, L.; Bernstein, B.; Sun, E. Concomitant administration of ABT 378/ritonavir results in clinically important pharmacokinetic interaction with atorvastatin but not pravastatin. Presented at the 40th 
Interscience Conference on Antimicrobial Agents and Chemotherapy, Toronto, Ontario, Canada, 17-20 September 2000; Abstract 334.

136. Samineni, D.; Desai, P.B.; Sallans, L.; Fichtenbaum, C.J. Steady-State Pharmacokinetic Interactions of Darunavir/Ritonavir With Lipid-Lowering Agent Rosuvastatin. J. Clin. Pharmacol. 2011, in press.

137. Kiser, J.J.; Gerber, J.G.; Predhomme, J.A.; Wolfe, P.; Flynn, D.M.; Hoody, D.W. Drug/Drug interaction between lopinavir/ritonavir and rosuvastatin in healthy volunteers. J. Acquir. Immune Defic. Syndr. 2008, 47, 570-578.

138. Kowa Pharmaceuticals America, Inc. Livalo (pitavastatin) tablets prescribing information. Available online: http://www.kowapharma.com/documents/LIVALO_PI_CURRENT.pdf (accessed on 8 September 2011).

139. Morgan, R.; Campbell, S.; Suehira, K.; Sponseller, C.; Yu, C.; Medlock, M. Effects of steadystate lopinavir/ritonavir on the pharmacokinetics of pitavastatin in healthy adult volunteers. Presented at the 6th International AIDS Society Conference on HIV Pathogenesis, Treatment and Prevention, Rome, Italy, 17-20 July 2011; Abstract MOPE 170.

140. Gerber, J.G.; Rosenkranz, S.L.; Fichtenbaum, C.J.; Vega, J.M.; Yang, A.; Alston, B.L.; Brobst, S.W.; Segal, Y.; Aberg, J.A. Effect of efavirenz on the pharmacokinetics of simvastatin, atorvastatin, and pravastatin: results of AIDS Clinical Trials Group 5108 Study. J. Acquir. Immune Defic. Syndr. 2005, 39, 307-312.

141. Touzot, M.; Beller, C.L.; Touzot, F.; Louet, A.L.; Piketty, C. Dramatic interaction between levothyroxine and lopinavir/ritonavir in a HIV-infected patient. AIDS 2006, 20, 1210-1212.

142. Lanzafame, M.; Trevenzoli, M.; Faggian, F.; Marcati, P.; Gatti, F.; Carolo, G.; Concia, E. Interaction between levothyroxine and indinavir in a patient with HIV infection. Infection 2002, $30,54-55$.

143. Gupta, S.K.; Dube, M.P. Exogenous cushing syndrome mimicking human immunodeficiency virus lipodystrophy. Clin. Infect. Dis. 2002, 35, E69-E71.

144. Hillebrand-Haverkort, M.E.; Prummel, M.F.; ten Veen, J.H. Ritonavir-induced Cushing's syndrome in a patient treated with nasal fluticasone. AIDS 1999, 13, 1803.

145. GlaxoSmithKline. Flonase (fluticasone propionate) nasal spray prescribing information. Research Available online: http://us.gsk.com/products/assets/us_flonase.pdf (accessed on 28 July 2011).

146. Kedem, E.; Shahar, E.; Hassoun, G.; Pollack, S. Iatrogenic Cushing's syndrome due to coadministration of ritonavir and inhaled budesonide in an asthmatic human immunodeficiency virus infected patient. J. Asthma 2010, 47, 830-831.

147. Penzak, S.R.; Formentini, E.; Alfaro, R.M.; Long, M.; Natarajan, V.; Kovacs, J. Prednisolone pharmacokinetics in the presence and absence of ritonavir after oral prednisone administration to healthy volunteers. J. Acquir. Immune Defic. Syndr. 2005, 40, 573-580.

148. GlaxoSmithKline. Serevent diskus (salmeterol xinafoate inhalation powder). Available online: http://us.gsk.com/products/assets/us_serevent_diskus.pdf (accessed on 28 July 2011).

149. Winston, A.; Back, D.; Fletcher, C.; Robinson, L.; Unsworth, J.; Tolowinska, I.; Schutz, M.; Pozniak, A.L.; Gazzard, B.; Boffito, M. Effect of omeprazole on the pharmacokinetics of saquinavir-500 mg formulation with ritonavir in healthy male and female volunteers. AIDS 2006, 20, 1401-1406. 
150. Lertora, J.J.; Rege, A.B.; Greenspan, D.L.; Akula, S.; George, W.J.; Hyslop, N.E., Jr.; Agrawal, K.C. Pharmacokinetic interaction between zidovudine and valproic acid in patients infected with human immunodeficiency virus. Clin. Pharmacol. Ther. 1994, 56, 272-278.

151. Dort, K.; Padia, S.; Wispelwey, B.; Moore, C.C. Adrenal suppression due to an interaction between ritonavir and injected triamcinolone: a case report. AIDS Res. Ther. 2009, 6, 10.

152. van Heeswijk, R.; Hoetelmans, R.; Kestens, D.; Stevens, M.; Peeters, M.; Williams, P.; Woodfall, B.; Boven, K. The pharmacokinetic interaction between ketoconazole and TMC278, an investigational non-nucleoside reverse transcriptase inhibitor (NNRTI), in healthy HIVnegative subjects. Presented at the XVI International AIDS Conference, Toronto, Ontario, Canada, 13-18 August 2006; Abstract TUPE0087.

153. Hamzeh, F.M.; Benson, C.; Gerber, J.; Currier, J.; McCrea, J.; Deutsch, P.; Ruan, P.; Wu, H.; Lee, J.; Flexner, C. Steady-state pharmacokinetic interaction of modified-dose indinavir and rifabutin. Clin. Pharmacol. Ther. 2003, 73, 159-169.

154. Borin, M.T.; Chambers, J.H.; Carel, B.J.; Gagnon, S.; Freimuth, W.W. Pharmacokinetic study of the interaction between rifampin and delavirdine mesylate. Clin. Pharmacol. Ther. 1997, 61, 544-553.

155. Borin, M.T.; Chambers, J.H.; Carel, B.J.; Freimuth, W.W.; Aksentijevich, S.; Piergies, A.A. Pharmacokinetic study of the interaction between rifabutin and delavirdine mesylate in HIV-1 infected patients. Antiviral Res. 1997, 35, 53-63.

156. Crauwels, H.M.; van Heeswijk, R.P.G.; Kestens, D.; Stevens, M.; Buelens, A.; Boven, K.; hoetelmans, R.M.W. The pharmacokinetic interaction between rifabutin and TMC278, an investigational NNRTI. Presented at the XVIIth International AIDS Conference, Mexico City, Mexico, 3-8 August 2008; Abstract TUPE0080.

157. Marzolini, C.; Telenti, A.; Decosterd, L.A.; Greub, G.; Biollaz, J.; Buclin, T. Efavirenz plasma levels can predict treatment failure and central nervous system side effects in HIV-1-infected patients. AIDS 2001, 15, 71-75.

158. Fletcher, C.V.; Anderson, P.L.; Kakuda, T.N.; Schacker, T.W.; Henry, K.; Gross, C.R.; Brundage, R.C. Concentration-controlled compared with conventional antiretroviral therapy for HIV infection. AIDS 2002, 16, 551-560.

159. Burger, D.; Hugen, P.; Reiss, P.; Gyssens, I.; Schneider, M.; Kroon, F.; Schreij, G.; Brinkman, K.; Richter, C.; Prins, J.; Aarnoutse, R.; Lange, J. Therapeutic drug monitoring of nelfinavir and indinavir in treatment-naive HIV-1-infected individuals. AIDS 2003, 17, 1157-1165.

160. Acosta, E.P.; Gerber, J.G. Position paper on therapeutic drug monitoring of antiretroviral agents. AIDS Res. Hum. Retrovirus. 2002, 18, 825-834.

161. LaPorte, C.J.L.; Back, B.J.; Blaschke, T.; Boucher, C.A.B.; Fletcher, C.V.; Flexner, C.; Gerber, J.G.; Kashuba, A.D.M.; Schapiro, J.; Burger, D.M. Updated guideline to perform therapeutic drug monitoring for antiretroviral agents. Rev. Antivir. Ther. 2006, 3, 4-14.

162. Acosta, E.P.; Henry, K.; Baken, L.; Page, L.M.; Fletcher, C.V. Indinavir concentrations and antiviral effect. Pharmacotherapy 1999, 19, 708-712.

163. Marzolini, C.; Buclin, T.; Decosterd, L.A.; Biollaz, J.; Telenti, A. Nelfinavir plasma levels under twice-daily and three-times-daily regimens: high interpatient and low intrapatient variability. Ther. Drug Monit. 2001, 23, 394-398. 
164. Gardner, E.M.; Burman, W.J.; Steiner, J.F.; Anderson, P.L.; Bangsberg, D.R. Antiretroviral medication adherence and the development of class-specific antiretroviral resistance. AIDS 2009, 23, 1035-1046.

165. Pretorius, E.; Klinker, H.; Rosenkranz, B. The role of therapeutic drug monitoring in the management of patients with human immunodeficiency virus infection. Ther. Drug Monit. 2011, 33, 265-274.

166. Veldkamp, A.I.; Weverling, G.J.; Lange, J.M.; Montaner, J.S.; Reiss, P.; Cooper, D.A.; Vella, S.; Hall, D.; Beijnen, J.H.; Hoetelmans, R.M. High exposure to nevirapine in plasma is associated with an improved virological response in HIV-1-infected individuals. AIDS 2001, 15, 1089-1095.

167. McFayden, L.; Jacqmin, P.; Wade, J.; Weatherley, B. Maraviroc exposure response analysis: phase 3 antiviral efficacy in treatment-experienced HIV+ patients. Presented at the 16th Population Approach Group in Europe Meeting, Kobenhavn, Denmark, 13-15 June 2007; Abstract 1172.

168. Boffito, M.; Acosta, E.; Burger, D.; Fletcher, C.V.; Flexner, C.; Garaffo, R.; Gatti, G.; Kurowski, M.; Perno, C.F.; Peytavin, G.; Regazzi, M.; Back, D. Therapeutic drug monitoring and drug-drug interactions involving antiretroviral drugs. Antivir. Ther. 2005, 10, 469-477.

169. Boffito, M.; Acosta, E.; Burger, D.; Fletcher, C.V.; Flexner, C.; Garaffo, R.; Gatti, G.; Kurowski, M.; Perno, C.F.; Peytavin, G.; Regazzi, M.; Back, D. Current status and future prospects of therapeutic drug monitoring and applied clinical pharmacology in antiretroviral therapy. Antivir. Ther. 2005, 10, 375-392.

170. Kappelhoff, B.S.; Crommentuyn, K.M.; de Maat, M.M.; Mulder, J.W.; Huitema, A.D.; Beijnen, J.H. Practical guidelines to interpret plasma concentrations of antiretroviral drugs. Clin. Pharmacokinet. 2004, 43, 845-853.

171. Ivanovic, J.; Nicastri, E.; Ascenzi, P.; Bellagamba, R.; De Marinis, E.; Notari, S.; Pucillo, L.P.; Tozzi, V.; Ippolito, G.; Narciso, P. Therapeutic drug monitoring in the management of HIVinfected patients. Curr. Med. Chem. 2008, 15, 1925-1939.

172. Thompson, M.A.; Aberg, J.A.; Cahn, P.; Montaner, J.S.; Rizzardini, G.; Telenti, A.; Gatell, J.M.; Gunthard, H.F.; Hammer, S.M.; Hirsch, M.S.; et al. Antiretroviral treatment of adult HIV infection: 2010 recommendations of the International AIDS Society-USA panel. JAMA 2010, 304, 321-333.

173. European AIDS Clinical Society Treatment Guidelines. Available online: http://www.europeanaidsclinicalsociety.org/images/stories/EACSPdf/1_treatment_of_hiv_infecte d_adults.pdf (accessed on 20 June 2011).

174. Antinori, A.; Marcotullio, S.; Ammassari, A.; Andreoni, M.; Angarano, G.; Carosi, G.; Cinque, P.; d'Arminio Monforte, A.; Di Perri, G.; Ensoli, B.; et al. Italian guidelines for the use of antiretroviral agents and the diagnostic-clinical management of HIV-1 infected persons. New Microbiol. 2011, 34, 109-146.

175. Miller, C.D.; El-Kholi, R.; Faragon, J.J.; Lodise, T.P. Prevalence and risk factors for clinically significant drug interactions with antiretroviral therapy. Pharmacotherapy 2007, 27, 1379-1386. 
176. Patel, N.; Abdelsayed, S.; Veve, M.; Miller, C.D. Predictors of clinically significant drug-drug interactions among patients treated with nonnucleoside reverse transcriptase inhibitor-, protease inhibitor-, and raltegravir-based antiretroviral regimens. Ann. Pharmacother. 2011, 45, 317-324.

(C) 2011 by the authors; licensee MDPI, Basel, Switzerland. This article is an open access article distributed under the terms and conditions of the Creative Commons Attribution license (http://creativecommons.org/licenses/by/3.0/). 